\title{
Extracellular Matrix (ECM)
}

\author{
Richard F. Helm and Malcolm Potts
}

\section{Contents}

Summary

18.1 Context of the ECM.

18.1.1 ECM - What's in a Name?

18.1.2 Old and New ECMs ....

18.1.3 Biophysical Considerations..

18.1.4 Jelly Bombs.

18.2 Cyanobacterial Lineage and the ECM.

18.3 Components of the Extracellular Matrix

18.3.1 Ecological and Physiological Overview

18.3.2 Cyanobacterial Exopolysaccharides

18.3.3 eDNA

18.3.4 Extracellular Proteins......

18.3.5 Non-reducing Oligosaccharides.

18.3.6 EPS-Protein Complexes.

18.3.7 Low Molecular Weight Substances (Secondary Metabolites)

18.4 Autoinduction Systems in Cyanobacteria

18.5 Oxidative Stress and Community Diversity

18.6 Future Prospects.

References

\section{Summary}

461

461

462

462

462

466

466

468

468

469

469

470

471 472

473 473

474 475 476

R.F. Helm ( ()

Department of Biochemistry, Life Sciences I, Virginia Tech,

Blacksburg, VA 24061, USA

e-mail: helmrf@vt.edu

\section{Potts}

Department of Biological and Environmental Sciences,

College of Arts and Sciences, Qatar University, POB 2713,

Doha, Qatar

e-mail: malcolm.p@qu.edu.qa

The region of space at the periphery of cyanobacterial cells is the interface between the environment and intracellular processes. This metaspace may include a structure appressed to the outer wall and membrane, such as an extracellular polysaccharide (EPS), a structural and/or physiological discontinuity modulating metabolite flow, as well as a temporal flux that accompanies stress or cell division. The functional framework within this region is designed to recognize environmental perturbations and relay physical and biochemical information to the cell interior, and perhaps to the cell community, for the appropriate physiological response. Communication between the environment and the cells is thus initiated within this extracellular milieu, which is therefore an important spatial domain in cyanobacteria. The ECM of cyanobacterial cells is multifaceted. It is not only a complex and dynamic mixture of polysaccharides, proteins, cell remnants and lower molecular weight secondary metabolites, but a hyperspace that tunes seasonal as well as shortterm stochastic modulations in environmental conditions. Such stresses result in changes in both the composition and organization of the matrix as cyanobacterial cells adjust to the environmental perturbations. This chapter provides a critical appraisal of the ecology and evolution of the cyanobacterial ECM compared with other prokaryotes. Emphasis is placed on how little is understood about this "occupied space" and several hypotheses and examples are presented in an effort to promote additional investigations of this oft-ignored interface.

\subsection{Context of the ECM}

The diversity of structural features of cyanobacterial cells and colonies emphasizes the complexity of the ECM and raise important questions about its functions and roles. 


\subsubsection{ECM - What's in a Name?}

A cursory perusal of any text in eukaryotic cell biology that deals with higher forms (Alberts et al. 2008) reveals the primary conceptual importance of the extracellular matrix (the ECM). Here ECM is equated generally with the non-cellular or "extracellular" part of a cell's environment that provides structural support as well as a myriad of other (somewhat less-defined) functions. The term matrix is very much emphasized as, or conceived as, a palpable, physical entity. With the advent of studies on bacterial biofilms (Stoodley et al. 2002; Costerton 2004; Stewart and Franklin 2008) the use of the term ECM in the context of prokaryotes came into use. Very soon, the term ECM became synonymous with EPS (extracellular polysaccharide) in bacterial colonies and populations. While one component of the cyanobacterial ECM is certainly attributed to EPS, the two should not be considered as being equivalent.

The etymology of the word "matrix" has its origins in the mid-sixteenth century deriving from "mother", "maternal" and "womb." One definition is: "A place or medium in which something is originated, produced, or developed; the environment in which a particular activity or process begins; a point of origin and growth" (OED 2009). The use of the word "environment" seems particularly appropriate here since it negates the concept of matrix as a solely tangible physical compartment. Rather, it emphasizes a zone of functionality; admittedly a more difficult concept to grasp and one that has, in addition, temporal attributes.

\subsubsection{Old and New ECMs}

Forms attributed to ancestral cyanobacteria had discontinuities at their cell surfaces that were sufficiently durable and conspicuous as to leave permanent traces in the fossil record (Chap. 2). Superficially, these structures seem comparable with the extracellular investments of contemporary cyanobacteria; has any functionality been retained to the present day?

In the classical taxonomic literature (Geitler 1932), much emphasis is placed upon the presence, absence, form, colour, texture, extent and development of a plethora of extracellular investments referred to variously as, in German for example, Scheide (meaning sheath, scabbard, border), as well as slimes, glycocalyces, and capsules. Less attention was paid to the complexity of these structures during the transition to the taxonomy sensu Rippka and co-workers (Rippka et al. 1979) based on axenic cultures. A primary reason for this was the common loss of interesting structural characteristics during prolonged laboratory culture. Nevertheless, "sheath absent" and "sheath present" are retained as determinative characters (Rippka et al. 1979), but one must question

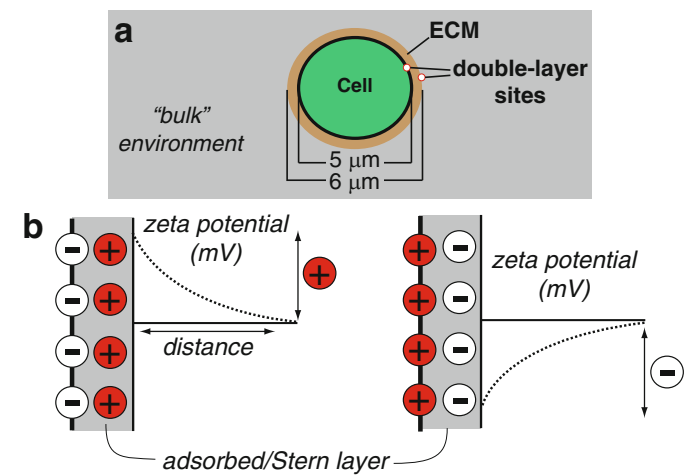

Fig. 18.1 Cells and cellular interfaces: (a) A unicellular cyanobacterium, depicted as a spherical cell, occupies a much larger space when producing an ECM. The outer membrane of the cell as well as the exterior surface of the ECM will have electrical double layers, the charge and magnitude of which will be dependent on cellular and bulk environmental conditions. (b) Depiction of electrical double layers. The outer membrane and the distal ECM face will have adsorbed counterions that provide a charge differential between the adsorbed layer and the environment. The charge will dissipate rapidly as the distance from the surface increases.

do these equate at the functional and conceptual level, respectively, with "ECM absent" or "ECM present?" For example, do the important members of marine picoplankton (Scanlan et al. 2009) of the genus Synechococcus (Section I, "sheath absent"; Chap. 20) have no extracellular matrix in the context of absence of a functional interface (EPS, sheath) with their environment? We think not. The concept of "extracellular" (EC) is easy to accommodate, but "matrix" conjures the sense of a physical scaffold, just one more layer of the cell, with no demarcation regarding functionality. Milieu (environment), i.e. extracellular milieu (ECM), seems a more appropriate term, but it may be harder to adopt at this point. For the rest of this discussion we use the term ECM loosely as a structural, functional and temporal region of ill-defined properties.

\subsubsection{Biophysical Considerations}

Consider the ECM of an ensheathed unicellular cyanobacterium with a cylindrical to ovoid cell of $5 \mu \mathrm{m}$ diameter that reproduces by binary transverse fission e.g. Gloeothece. In reality, such an ovoid has a quadratic surface that may be somewhat prolate (elongated) or oblate (flattened). However, for the purposes of this first example consider the simplest scenario where the cell is a sphere (Fig. 18.1a). In this case, the extracellular compartment would typically add an additional $0.5 \mu \mathrm{m}$ thickness to give a total diameter of $6.0 \mu \mathrm{m}$. The volume of the ECM is $47.6 \mu \mathrm{m}^{3}$, representing $42 \%$ of the total three-dimensional space occupied by the individual cell (ball). This is a substantial volume in comparison to that of the cell interior. Furthermore, addition of this zone to an 
otherwise "naked" cell increases the available surface area by $44 \%\left(78.6-113 \mu \mathrm{m}^{2}\right)$. If one considers that such a cell is tumbling through a water column, then this can be considered a starting point to consider how that cell interacts either with molecules undergoing molecular diffusion to or from the surface of the ECM, or with objects on the size scale of other cells ("self" or epiphytes), cyanophages or solid surfaces.

It is important to make the distinction between the functional ball of the cell, the space extending out from the cell, and the extreme distal face of the ECM in contact with the environment. Each of these boundaries will have electrical double layers of ill-defined charges and thicknesses (Fig. 18.1b). The charge difference between the surface and bulk fluid is termed the zeta potential, and has been measured in a limited number of cyanobacteria (Dittrich and Sibler 2005; Martinez et al. 2008, 2010). These charge states must be accommodated when posing questions and hypotheses about the structure and function of the cyanobacterial ECM. In addition, one must consider if there are regions of temporal transfer hyperactivity at the outer surface of the ECM. In other words, is the three-dimensional ECM (essentially a hollow sphere of finite thickness possessing an electrical double layer) homogenous? What controls determine "departure" from the junction of the distal surface of the outer cell membrane and proximal face of the ECM, "travel" in the ECM, and "arrival" at the distal extremity of the ECM (bulk fluid); and vice versa? In this example the cell's environment was aqueous. What if the environment is aerophytic with sporadic hydration? This will surely increase the complexity of the ECM regiochemical dynamics.

To further develop the context of the ECM, consider an example where an ensheathed cell is spherical, but divides in two or three successive planes at right angles to one another. This is to emphasize that unless one invokes synchronization, and we are not ruling that out, the cells may be at different stages of division at any point in time when they may be forced to undergo metabolic arrest. Now, consider many tens, hundreds, thousands, of these cells, depending on the maturity of the colony, encased (immobilized?) in a second ECM2; essentially a multicellular aggregate. This, in fact, is the situation for Gloeocapsa cf sanguinea growing on roof shingle (Fig. 18.2). In simplistic terms, one can consider the cells as particles within the ECM2; the system is colloidal, with the ionic strength of the bulk fluid influencing the magnitude and extent of the electrical double layers. Colonies of Gloeocapsa, with a range of diameters, become stacked and distributed over the substrate, where they appear as associated spheroidal colonies when viewed in the low power light microscope (Fig. 18.2e). This provides a further dimension to the ECM (i.e. ECM3). Consider one colony of $500 \mu \mathrm{m}$ diameter. If only $1 \%$ of the three-dimensional space of ECM2 were available for occupancy, approximately
5,700 cells ( $3 \mu \mathrm{m}$ radius) would be encased. If $50 \%$ of the space was comprised of cells, then 290,000 could be accommodated.

One reason to consider these hypothetical numbers is that microscopic examination of such colonies, and typically many other types collected from field settings e.g. marine Gomphosphaeria spp., reveals an apparently ordered geometric distribution of the particles (cells) where no two appear to be in direct contact with another. How could this occur since it seems a violation of thermodynamics? Model experiments with different sized spheres, suspended in water, identified the depletion force, which is entropic in nature and can lead to such ordering in colloidal systems (Cates et al. 2010; Marenduzzo et al. 2006). Such experiments in condensed matter physics may shed much light on the dynamics of the ECM in cyanobacterial communities. Also, application of so-called Voronoi tessellation analysis may be informative (Kumar and Kumaran 2005; Rycroft et al. 2006). In such an analysis one can consider the colony (big ball ECM2) as a system of monodisperse spheres (cells ECM1). The centre of each cell defines a unique set of points within the space of the colony and the resulting Voronoi tessellation is used to study the packing properties of the colony through computer simulation. If the monodisperse cells are non-overlapping, as they are in the Gloeocapsa colony, then each sphere (cell with its ECM1) is completely contained within its Voronoi "cell" (Voronoi terminology "cell" is tantamount equivalent to "zone"). Such a "zone" has physical attributes that may be more representative, conceptually, of the ECM in the way that we envisage it to be. The "flow" of cells in this colloidal Gloeocapsa system may be slow, in view of the viscosity of the ECMs, but one must emphasize that such flow is still subject to the effects of gravity.

At this point, there has been no discussion of how the Gloeocapsa system (with its ECM1 and ECM2, distinct structures, and the additional physical dimension of colony stacking giving ECM3), responds to environmental perturbation. Removal of water from this system through desiccation leads to time-dependent shrinkage of the ECMs and cells, loss of structure, the geometry and packing of the system collapses and cells are now in close contact. This is not unexpected considering the principle role of water. What is confounding however, is that upon subsequent rehydration of the colony, all of the geometry, spatial structure and cell distribution is recovered.

The complexity of this seemingly nondescript roof film is emphasized by the regular three-dimensional distribution of cells within spheres of ECM2 (Fig. 18.2), raising the same types of questions as formulated by Schaudinn et al. (Schaudinn et al. 2007) with regard to the presence of "geometric order" in biofilms. How can the three-dimensional distribution of cells within an aerophytic community biofilm (ACB) be maintained during multiple cycles 
a
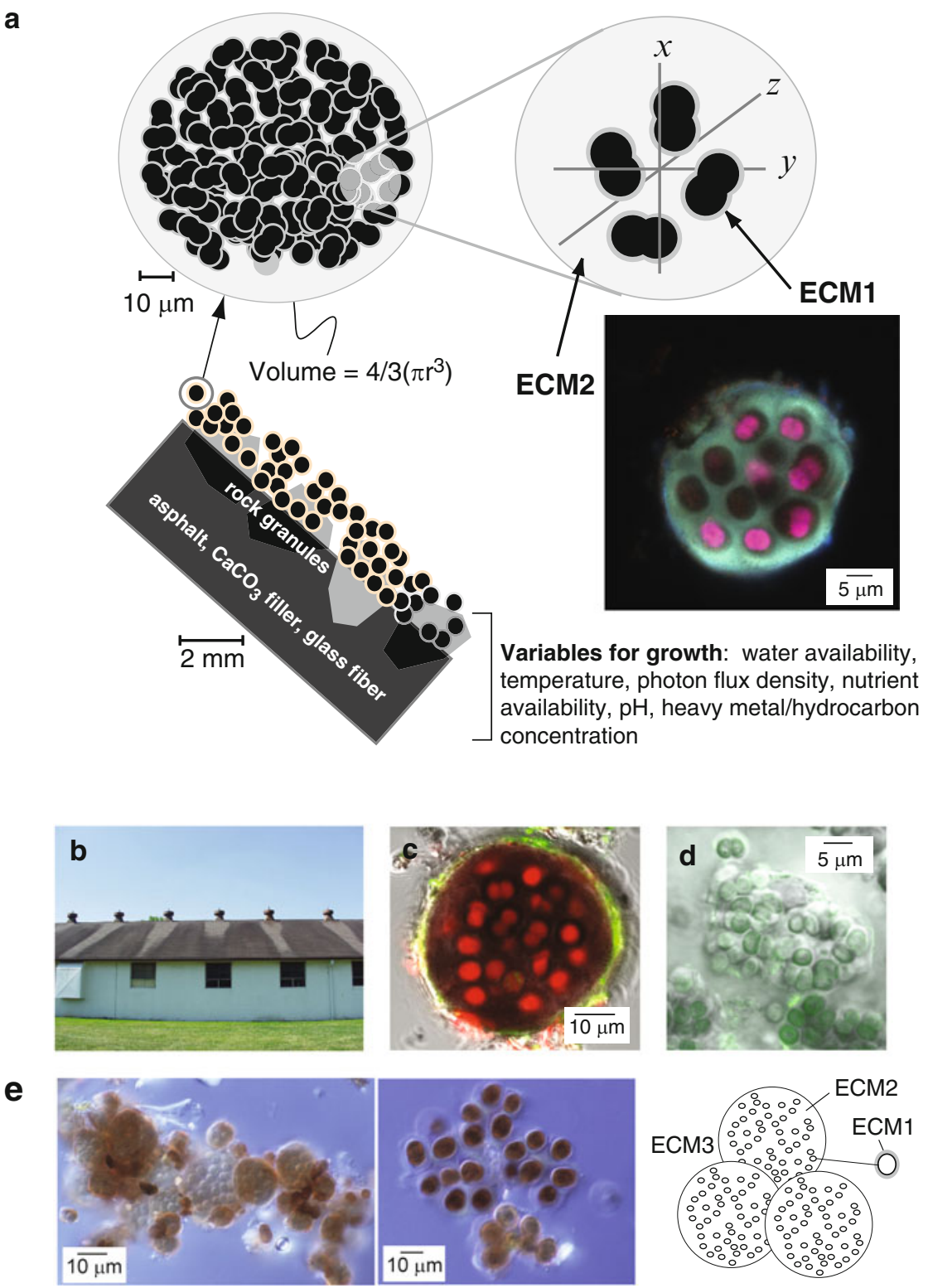

Fig. 18.2 Essential features of the Gloeocapsa ECM: (a) Roof shingle contains an asphalt base, calcium carbonate filler, and glass fiber, with rock granules embedded in the matrix at the time of manufacture. Colonies of Gloeocapsa grow on, around, and between the rock granules, as well as on the asphalt itself. Single colonies have the shape of spheres when hydrated, and contain numerous cells distributed within a polysaccharide matrix (EPS) infiltrated with UV-absorbing pigments, proteins, metabolites and potentially nucleic acids. Combined, this region is referred to as the outer extracellular matrix (ECM2). Note that when hydrated each cell is also bound by a thin, inner ECM (ECM1). (b) Abundance of the biofilm can be judged from a comparison of

of desiccation (shrinkage and thus cell-cell contacts), subsequent rehydration, heating and freezing? Currently it is thought that ECM provides this capability, but we have no plausible explanation for the underlying controls that would permit this. mature community and regions where growth is inhibited by the leaching of metals from roof ducts. (c) In these hydrated colonies, no one dividing cell comes into contact with its neighbors; the cells are equally distributed within the spherical, 3-dimensional ECM with a clearly defined distal face. During removal of water and desiccation the outer ECM collapses so that cells either make contact or, remain separated by a biophysical glass with a thickness on the nanometer scale. Upon rehydration, the spherical distribution of cells within ECM is re-instated. (d) Laboratory planktonic growth results in a more crowded and less organized ECMencased community. (e) Associations of individual colonies leads to the development of ECM3.

The last two examples consider cyanobacteria of Section IV (filamentous heterocystous cyanobacteria that divide in only one plane (Rippka et al. 1979)); specifically Nostoc commune and forms where the trichome is tapered and a hair is formed (Chap. 22). 

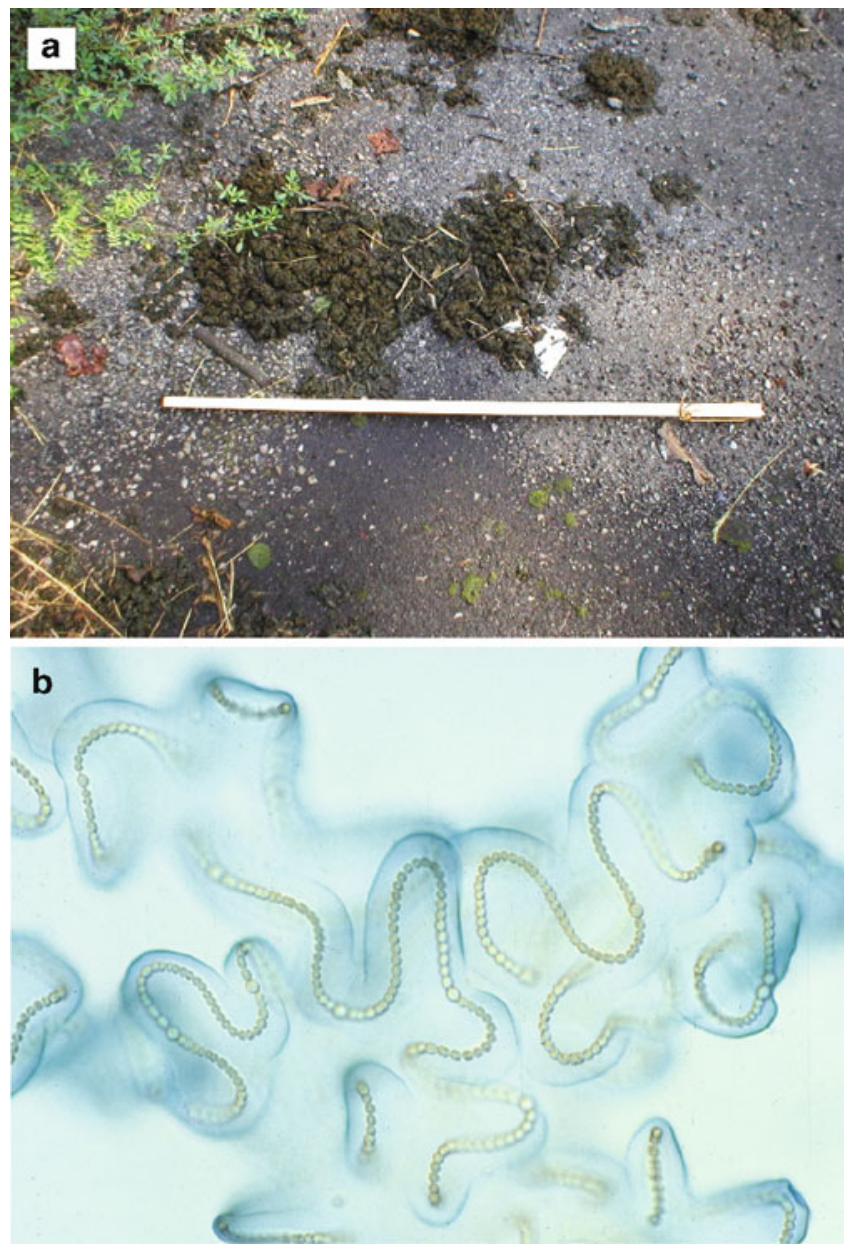

Fig. 18.3 Nostoc commune produces significant amounts of ECM: (a) The organism can form large clusters of a gelatinous biomass when fully hydrated (a yardstick is shown for scale); (b) ECM2 is readily evident via Alcian Blue staining when $N$. commune is grown in culture. Note the lack of interaction between adjacent ECMs (Field photo courtesy of Jody and Charles Jervis).

The life cycle of Nostoc commune was reviewed by Potts (2000) and the properties of its ECMs by Wright et al. (2005); temporal aspects of ECM function are considered here. According to the prevailing environmental conditions, filaments of Nostoc may consist of one or more of three cell types: vegetative cells, heterocysts and, in some forms, akinetes. The EPSs of these three cell types may be of different composition (see details later in this chapter) therefore, one must question the differences in the structure and function of their respective ECMs. Through analogy with Gloeocapsa sanguinea (above), filaments of Nostoc commune, potentially with predominant $\mathrm{ECM} 1_{\mathrm{VEG}}$, and less so $\mathrm{ECM} 1_{\mathrm{HET}}$ and ECM $1_{\mathrm{AKI}}$ are embedded within an ECM2 that constitutes the bulk of spherical gelatinous colonies (staining with $\mathrm{pH}$-dependent dyes reveals this bulk is non-homogenous). In comparison to the spherical colonies of Gloeocapsa the colonies of Nostoc spp. may be much larger (Fig. 18.3). In these colonies,
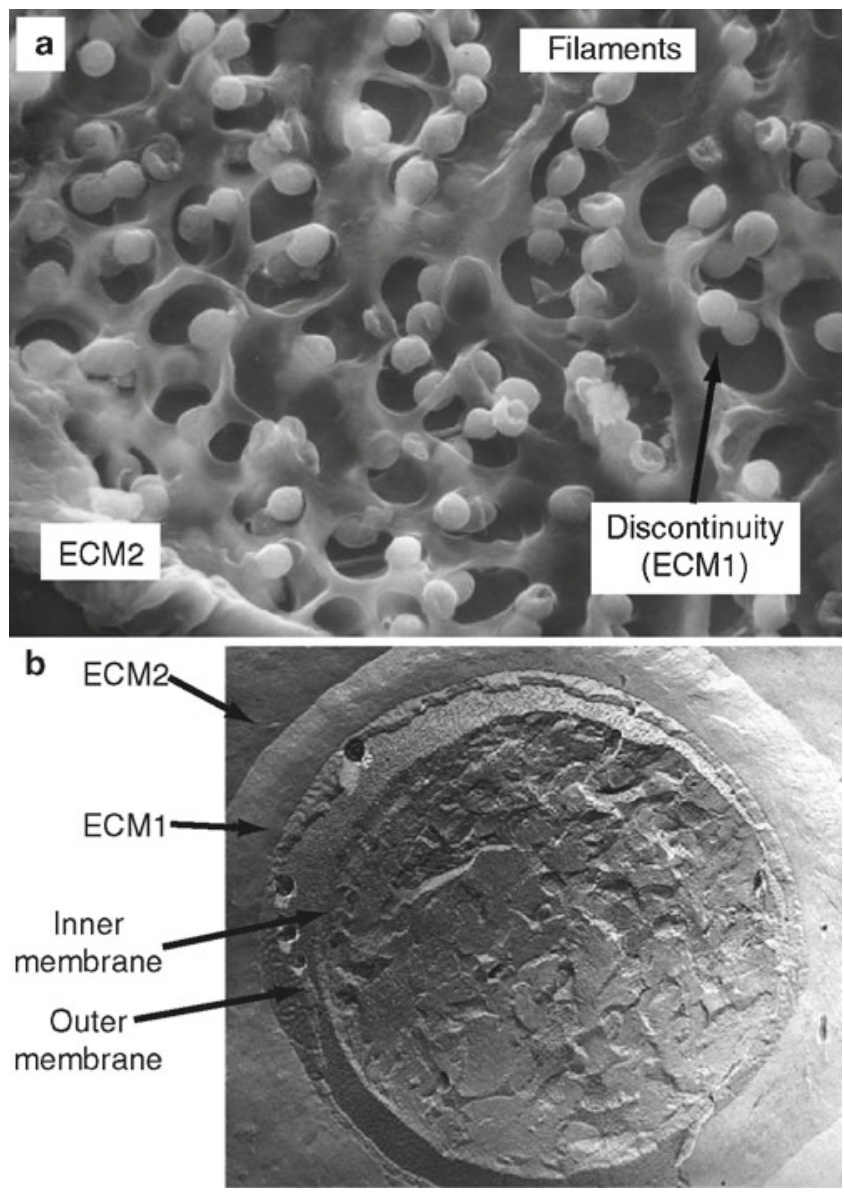

Fig. 18.4 Nostoc commune ECM zones are readily evident using electron microscopy: (a) When submitted to critical point drying and electron microscopy, filaments separate from the ECM2 to create zones of discontinuity, presumably a space between ECM1, which contacts the outer membrane, and ECM2. (b) Freeze fracture electron microscopy reveals the orderly composite nature of the cell as well as its extracellular investments. ECM2 is clearly separate from the zone of discontinuity, an ill-defined region termed presently as ECM1. The double membrane system of the cell is also indicated.

the prospect for filament-filament contact again appears slim, which again raises the questions: is there signaling for such three-dimensional distribution and, if so, why, and how?

Important details of the structure and biochemistry of the ECM of $N$. commune DRH1 and field materials were obtained by Hill et al. (1994a,1997). Freeze fracture electron microscopy provided conclusive evidence for a zone of "discontinuity" at the immediate surface of the cells with chemical and rheological properties distinct from the bulk of the "glycan" (EPS; Fig. 18.4). Interestingly, this zone simply appears as a translucent electron-transparent region when specimens are viewed in the transmitted electron microscope, which was interpreted by others as shrinkage of the EPS from the cells during sample preparation. We hypothesize that the zone of "discontinuity" contains one or more volatile components that are removed during preparation for TEM; low 


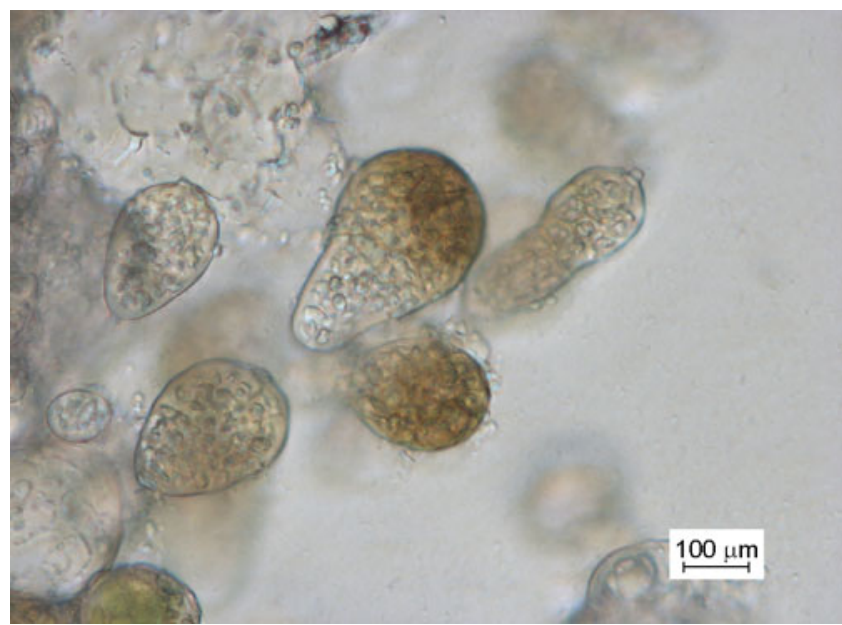

Fig. 18.5 Aseriate growth of Nostoc commune results in a different ECM phenotype. Soil-grown isolates from a greenhouse on the campus of Qatar University were cultured in the laboratory. Note the pear-shaped ECM2 encases the entire community. Amber colour due to scytonemin.

molecular weight carbohydrates and/or lipid, and water. Note that a similar translucent region was seen in the Gloeocapsa confocal images in a fully hydrated state (Fig. 18.2)

At some point in the life cycle of Nostoc commune the EPS component(s) of ECM1 $1_{\mathrm{VEG}}$ in a filament (seriate phase) undergoes physical and chemical changes that make it more prominent, rigid and non-expansive. As cell division of the filament continues, the filament is forced to occupy diminishing three-dimensional space due to the increase in its length. Ultimately, this leads to the formation of an ovoid structure, packed with a contorted filament (under pressure?), linked via a single heterocyst (because this cell cannot divide), to another packed ovoid. These "balls" are referred to as the aseriate stage of $N$. commune (Fig. 18.5). Subsequently, for reasons unknown, the ECM $1_{\mathrm{VEG}}$ undergoes changes that lead to the bursting of the aseriate masses, and subsequent release and growth of hormogonia and the seriate phase is recovered. In the aseriate phase of $N$. commune in Fig. 18.5 (grown on agar) there is a definite physical polarity of the ECM2 encasing the trichome, with localized production of the photoprotective scytonemin. In the following example, we also discuss polarity and localized production of scytonemin but at the level of a single trichome with ECM1.

Rivularia may also have $\mathrm{ECM} 1_{\mathrm{VEG}}$, and less so $\mathrm{ECM} 1_{\mathrm{HET}}$ and $\mathrm{ECM} 1_{\mathrm{AKI}}$, but here there are some subtle differences. The heterocysts are at one end, and vegetative cells become diminished in size and volume the more distal from the heterocyst so that a tapered filament often ending a hair develops (Chap. 22). The filaments, within a bulk EPS of the ECM2, form semi-spheroid colonies that attach on solid substrates and receive a flow of water and nutrients, typically in streams. In these semi-spheroidal colonies, the heterocystous end of each filament is orientated to the centre of the colony, with the hairs radiating out towards the surface of the colony. With some modifications this is true for other forms in Section IV including marine Isactis and Gardnerula spp. (Potts 1980). The flux, temporal change in gradients, and dynamics of the ECM in colonies of Rivulariaceae, Gloeocapsa cf sanguinea and Nostoc commune, with respect to stressors, must be very different, and no doubt reflect subtle differences in their respective genomes.

\subsubsection{Jelly Bombs}

A bizarre example of a cyanobacterial ECM that extends for several square kilometres is found in Storr's Lake; an approximately $2 \mathrm{~m}$ deep, orange-coloured, saline, sulphiderich coastal pond on the island of San Salvador, Bahamas (Paerl et al. 2003). The predominant cyanobacterium is Aphanothece, which produces ECM biomass in the order of $10^{5} \mathrm{~kg} \mathrm{~km}^{-2}$ (assuming a finite third dimension of $2 \mathrm{~m}$ depth). Prevailing wind drives the ECM ashore as a conspicuous carbohydrate-rich foam (Fig. 18.6a). In addition, equallyweird benthic growths of non-heterocystous cyanobacteria form "Jelly Bombs" (or "Ectoplasm Growths" and "Pie Mounds") (Fig. 18.6b, c). These rubbery, gelatinous colonies, when dried and desiccated, easily break a steel scalpel blade upon attempts to obtain sections, emphasizing the pervasive role of water in the structure and function of ECMs.

From the air, Storr's Lake is seen as a bright orange basin against the grey of the island's limestone karst. Flights over many other islands in the Bahamas suggest that counterparts of Storr's Lake are numerous.

\subsection{Cyanobacterial Lineage and the ECM}

The phylogenetic analysis of prokaryotic evolution utilizing techniques considered to avoid the complexities of horizontal gene transfer (HGT) (Zhaxybayeva et al. 2006) focus on the comparison of so-called "core proteins;" translated products from genes that exhibit reduced levels of HGT (SanchezBaracaldo et al. 2005; Shi and Falkowski 2008; Swingley et al. 2008; Gupta 2009; Gupta and Mathews 2010). A study utilizing such techniques placed the Cyanobacteria with the Actinobacteria, Chloroflexi, Firmicutes and DeinococcusThermus phyla and referred to subsequently as a terrestrial clade (Battistuzzi and Hedges 2009). Lake (2009) analyzed prokaryotic phylogenies based upon the hypothesis that the cyanobacteria (as well as the other double membrane bacteria) were derived from an ancient endosymbiosis event, and suggested that the cyanobacteria were derived from the endosymbiosis of a clostridium and actinobacterium. The characterization 
Fig. 18.6 Storr's Lake is a high salt environment with conspicuous levels of ECM materials: (a) When washed upon the shore, the EPS forms a foam-like material ("candy floss"); (b, c) "Jelly bombs" are visible as benthic growths on the water as well as in the sediment (Photos courtesy of H.W. Paerl).
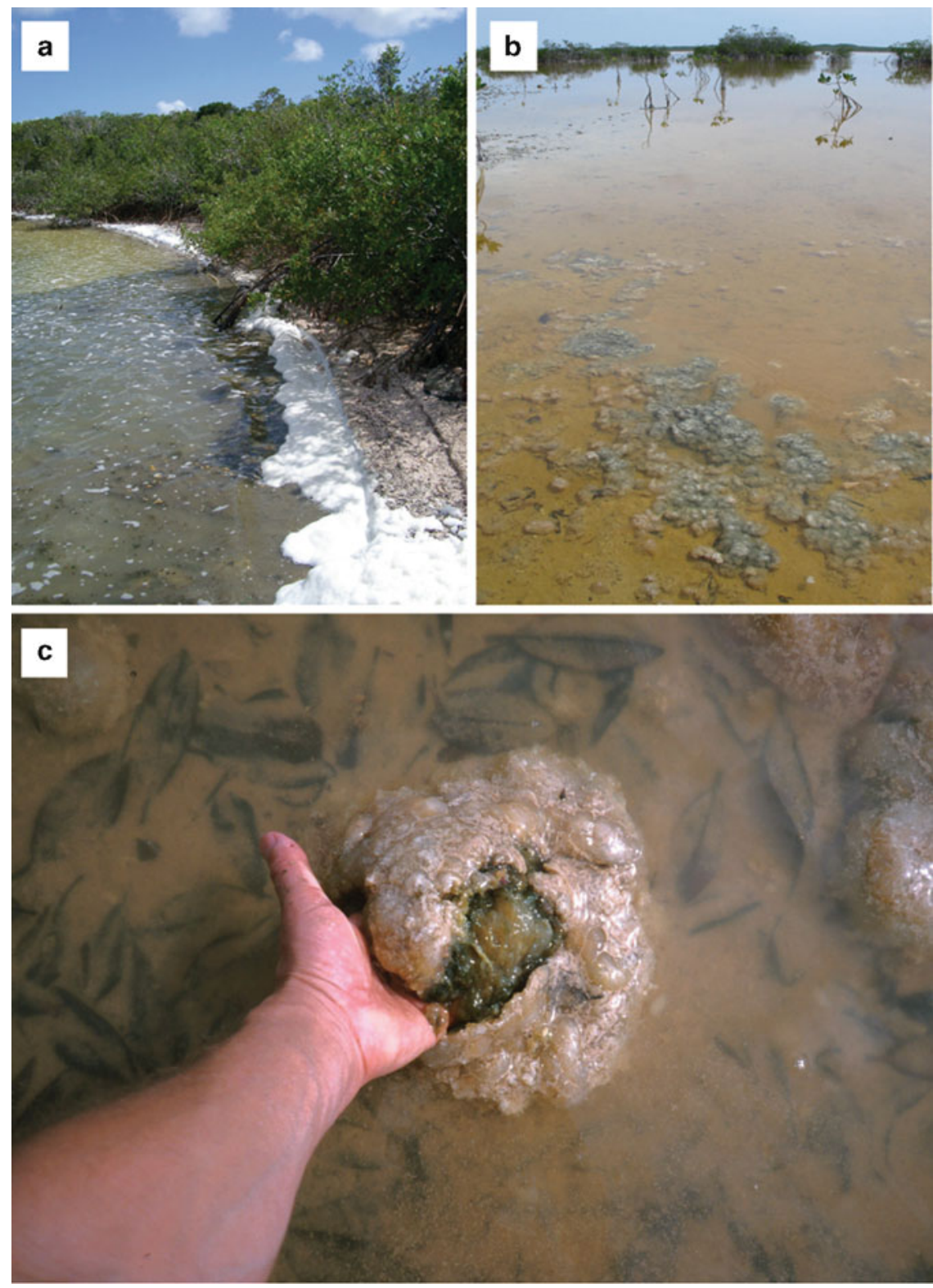

of the protein signatures of 44 sequenced cyanobacteria led to the assignment of three separate clades (Gupta and Mathews 2010). One clade, designated Clade B, contained the majority of known cyanobacteria, including the heterocystous forms. Signature analyses placed the Oscillatoriales in between the orders Nostocales and Chroococcales. Despite the sophistication of such analyses, attempts to mesh data with the realities of structure and function in field populations are relatively rare (Schirrmeister et al. 2011). Emphasis is consistently placed on nucleic acid and protein sequences, with little attention paid to functional evolution. As emphasized elsewhere, the concept of little to zero evolutionary change over geological time (hyperbradytely) is one that is special to the cyanobacteria (Chap. 2) and deserves equal consideration at the levels of metabolism, protein structure/function, and the ECM.
Nonetheless, sequence-based analyses provide insight into the diversity and evolution of the cyanobacterial phylum. This diversity is exemplified by the ubiquitous presence of cyanobacteria in almost all environments that are exposed to a source of light-aquatic, marine and terrestrial. In our work with aerophytic community biofilms (ACBs; also termed subaerial biofilms or SABs), such as those found on solid substrates (stone or roof shingle), the individual communities that develop are both complex and dynamic (Gorbushina and Broughton 2009). Complex by the fact that even cursory phylogenetic analyses with one marker (group I introns), point to a continuum, at least within one morphological subgroup (coccoid cyanobacteria) (D.J. Wright, R.F. Helm, M. Potts, unpublished data). In fact, for a set of Gloeocapsa cf sanguinea samples evaluated in our laboratory, 
there was no obvious indication of the beginning, or end, of the continuum of forms. Such communities are dynamic in the sense that the assemblage of forms inhabiting the biofilm is subject to rapid fluctuations in metabolic activity in response to environmental extremes, imposed in different permutations, over time. For example, desiccation leads to full metabolic arrest, sometimes for protracted periods. During summer, desiccated ACBs reach temperatures of $100^{\circ} \mathrm{C}$ or greater. At such temperatures, how do cells respond to a transitory rain shower (thunderstorm), accompanied by convective cooling, metabolic activation, and then rapid drying and heating back to $100^{\circ} \mathrm{C}$, perhaps multiple times over a period of minutes/hours? Under such environmental extremes, what mechanisms and/or processes are in place to permit a continuum of forms at the genetic level with little apparent evolutionary form change at the geological time scale?

\subsection{Components of the Extracellular Matrix}

\subsubsection{Ecological and Physiological Overview}

The most abundant component of a fully hydrated cyanobacterial ECM on a mass basis is water; the second is polysaccharide. Such exopolysaccharides are heterogeneous in carbohydrate composition and may, or may not, have pendant groups such as acetate, sulphate and lactyl groups (Pereira et al. 2009). Generally anionic in nature, these polymers contribute to the structural framework of the ECM, and can be found either loosely surrounding the cells or released to the medium in which the cells are growing. The associated (tightly-bound) polysaccharides are often referred to as sheaths, capsules or slimes, whereas the polysaccharides found in the media are generally referred to as released polysaccharides (RPS). The relationship between the associated and released materials is not fully resolved. Based upon observed differences in chemical characterization, it can be hypothesized that they are derived from separate biosynthetic processes, the result of changes in the monomer and pendant group inputs on the same assembly machinery, or modulation of the outer membrane surface properties.

The roles of the EPS can be summarized using the terrestrial cyanobacterium Nostoc commune as an example. Colonies of $N$. commune are a conspicuous feature of many terrestrial soils from the tropics to the polar regions (Potts 2000). Desiccated crusts are brittle and friable, but have the consistency of cartilage when rehydrated. The rapid swelling of desiccated colonies following rainfall is sufficiently striking that it was even the subject of medieval folklore (Potts 1997). This marked capacity for desiccation tolerance (Wright et al. 2005) is linked to the EPS, as this material can inhibit fusion of membrane vesicles during desiccation and freeze drying (Hill et al. 1997), with the anionic polysaccharide providing the repulsive forces that lead to rapid swelling. The glycan is a slowly diffusing/immobilized matrix for a range of secreted enzymes that are active upon rehydration (Peat et al. 1988; Scherer and Potts 1989; Shaw et al. 2003; Morsy et al. 2008), providing a structural and/or molecular scaffold with rheological properties that can accommodate the rapid biophysical and physiological changes that occur upon recovery from stresses such as desiccation. The glycan swells from brittle dried crusts to cartilaginous structures within minutes of rehydration. The matrix contains both lipid- and watersoluble UV radiation-absorbing pigments, protecting the cytosolic components, to some degree, from photodegradation. Finally, although epiphytes colonize the surfaces of Nostoc colonies, penetration into the interior is limited due in part to a silicon- and calcium-rich pellicle and inherent resistance of the glycan to enzymatic breakdown. Preliminary structural work on one water-soluble UV-absorbing pigment (released from the glycan by acid hydrolysis) indicated the presence of an oligosaccharide (Bohm et al. 1995), raising the possibility that the pigment may be covalently linked to the glycan in the desiccated state. An understanding of the biochemical and biophysical properties of such biopolymers and the isolation of genes and enzymes required for their synthesis and modification can lead to an understanding of the underlying principles of extremophile stability. Furthermore, one can envision the utilization of such materials for the commercial stabilization of labile agricultural chemicals, food, pharmaceuticals, and/or biomedical materials.

The extracellular matrix is also involved in more largescale ecological processes. In arid terrestrial environments, cyanobacteria are involved in soil development via the ECMmodulated aggregation of soil particles. These "crusts" help keep soil particles in place and maintain moisture levels for increased lengths of time (Garcia-Pichel and Pringault 2001; Yeager et al. 2007; Chen et al. 2009; Garcia-Pichel and Wojciechowski 2009). Carbon and nitrogen fixation provide long-term soil amendment leading to eventual increases in biological productivity. These subaerial biofilms (SABs) can contribute to weathering of solid surfaces, often leading to detrimental effects as can be seen in the fouling of historical structures (Barberousse et al. 2006; Gorbushina 2007; Macedo et al. 2009). Such SABs are mutualistic in nature as indicated by the shift in $N$. punctiforme growth from filamentous to aseriate when exposed to the yeast Sarcinomyces petricola (Gorbushina and Broughton 2009). It is important to emphasize that cyanobacteria, with their associated ECMs, colonize all substrates from plankton (Chap. 20), to solid rock (marine endolithic Mastigocoleus Kyrtuthrix, as well as terrestrial chasmoendolithic Chroococcidiopsis). In addition they enter into symbiotic associations (Chap. 23). All of these different environments must present unique interfaces for contact between the cyanobacterial ECMs and the environment. 


\subsubsection{Cyanobacterial Exopolysaccharides}

The polysaccharides that provide the bulk of the biomass in the ECM are quite diverse in structure, and the known polysaccharide structures and the factors affecting their production have been summarized (Pereira et al. 2009). While no complete studies have been published that define all variables for a particular strain, a supply of nitrogen and high light generally lead to increased polysaccharide production. Uronic acids are the typical source of the anionic character, along with pyruvate and sulphate moieties, with generally between 4 and 8 different monosaccharides comprising the polysaccharide backbone.

The EPS biosynthetic process in cyanobacteria is illdefined. The currently available literature on other organisms, as well as data from sequenced genomes, led to the hypothesis that assembly occurs within the inner membrane, with the newly formed products passing through the periplasmic space (Pereira et al. 2009). In the case of filamentous, heterocyst forming cyanobacteria, this must be a highly coordinated event, both biochemically and spatially. Transverse passage through the periplasmic space must occur simultaneously with axial movement of materials between cells (Whitfield and Naismith 2008; Cuthbertson et al. 2009; Flores and Herrero 2010). Once through the periplasmic space, exit through the outer membrane leads to either loosely or tightly bound glycan. The monosaccharides present in cyanobacterial exopolysaccharides are quite diverse and are thought to have temporal and environmental response components (Pereira et al. 2009). While a sigma factor has been identified (Yoshimura et al. 2007) that modulates EPS production in Anabaena sp. strain PCC7120 (sheathless and devoid of S-layers), little more is known about the process. Although production rates can be linked to nutrient supplies and cell type (vegetative vs. heterocyst), more specific details are lacking. S-layers (proteins) are foci of calcification (Chap. 16) and could potentially be involved in mineral extraction/utilization processes and also considered a component of the ECM.

Previous reports on the extracellular polysaccharides of cyanobacteria suggest that their structures may not be comparable to those of algae, bacteria or fungi (Morvan et al. 1997; De Philippis and Vincenzini 1998; Helm et al. 2000). The presence/absence of a repeat unit and/or specific polydispersities within isolated polysaccharides are considered unanswered questions. In our work it appeared that the $N$. commune EPS does contain a predominant repeat unit when grown under the specific conditions. There is some degree of flexibility in the sequence of, and control over, the polysaccharide assembly process. As a consequence, cyanobacteria may produce polysaccharides with a specific linkage pattern under one set of conditions but, as the environmental cues change (extreme heat, lack of water, prolonged laboratory culture), the polysaccharide structure may be modified to insure the viability of the organism. This makes structural analysis of the polysaccharides quite challenging, especially for field materials, as they may contain several polysaccharides, each representing the recent environmental history of that location. Such behaviour is not without precedent, as we reported different amounts of nosturonic acid in field-grown materials of $N$. commune from different geographic locations (Helm et al. 2000).

Cyanobacteria such as the Nostocales must have EPS export processes to provide LPS and EPS for at least two different cell types:vegetative cells and heterocysts. As several of these can also have motile (hormogonia), spore-like (akinetes) and aseriate states, additional machinery may be required, or the biosynthetic systems may be modified to permit changes in production rates and formation of different structures/types/ forms. Continued research on the biosynthesis of EPS in cyanobacteria will provide new insights into EPS production processes, a better understanding of the role of the periplasmic space in transverse and longitudinal molecular transport processes, the role of EPS in movement (Hoiczyk and Hansel 2000; Garcia-Pichel and Pringault 2001; Read et al. 2007), multicellularity (Lehner et al. 2011) and higher order structures (Garcia-Pichel and Wojciechowski 2009).

\subsection{3 eDNA}

Biofilm structures in many organisms appear to require the presence of extracellular DNA to form organized matrices. It was reported that eDNA is one of the components of the ECMs of several prokaryotes (Whitchurch et al. 2002), with values on the order of $\mu \mathrm{g} \mathrm{eDNA} / \mathrm{mL} \mathrm{OD}_{600}$ of cells (Wu and $\mathrm{Xi}$ 2009). Due to its high phosphorus content, eDNA is important in deep-sea ecosystems (Dell' Anno and Danovaro 2005). Interestingly, extracellular DNA production is not only species dependent, but community dependent as well (Steinberger and Holden 2005). This eDNA is associated generally with initial colonization processes, and DNase treatment strategies can elicit biofilm dispersal. Addition of genomic or salmon sperm DNA to young cultures of Listeria monocytogenes could not restore the adherence unless a peptidoglycan was added as well (Harmsen et al. 2010), although this was not the case with Neisseria meningitides, where the addition of DNA alone restored biofilm adherence (Lappann et al. 2010). Mature biofilms are significantly more resistant to DNase treament than young colonies, leading to the hypothesis that eDNA is intricately woven into the ECM fabric, where enzymatic breakdown is difficult due to spatial constraints. The most tenable hypothesis on the source of the eDNA is cellular lysis of a subpopulation of cells (Allesen-Holm et al. 2006; Karatan and Watnick 2009). Whether or not eDNA is an integral component of cyanobacterial ECMs and/or what role cell lysis has on this process has yet to be fully investigated. 


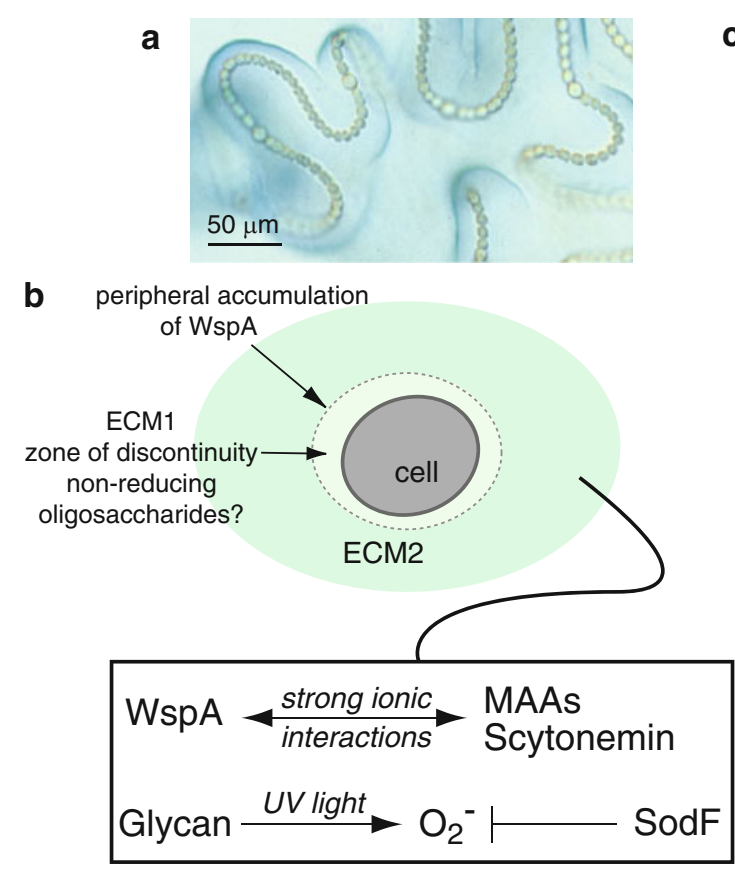

Fig. 18.7 Model of ECM structure and function: (a) Alcian blue staining of a liquid culture of $N$. commune DRH1 showing seriate filaments and different rheologies of the glycan (corresponding to different staining levels). (b) Model for the extracellular matrix of $N$. commune. WspA is present throughout the glycan, but accumulates at the periphery of a discontinuity in the glycan surrounding cells.

\subsubsection{Extracellular Proteins}

Proteins released from cellular confinement are often referred to collectively as the secretome. This definition is somewhat problematic for microbial systems that release small peptides, as well as the fact that cell lysis will generate a constellation of proteins that may or may not contribute to cellular responses. Scanlan and Carr (Scanlan and Carr 1988) defined extracellular proteins as those selectively enriched in cellfree media with a mass of greater than $10 \mathrm{kDa}$ and suggested that isolates that are free of light-harvesting biliproteins are true secreted proteins. The filamentous cyanobacterium Nostoc commune releases significant quantities of the waterstress protein (WspA) and superoxide dismutase (SodF) as a result of desiccation and UV stresses (Scherer and Potts 1989; Hill et al. 1994a; Wright et al. 2005). Extracts of these materials exhibit xylanase activity. WspA and SodF are both secreted in substantial amounts past the outer membrane of N. commune (Shirkey et al. 2000; Ehling-Schulz et al. 2002), yet neither have any recognizable $\mathrm{N}$-terminal signal sequence. A putative C-terminal signal sequence was identified in WspA, but not in SodF (Wright et al. 2005).

The isolated extracellular glycan of $N$. commune DRH1 generates superoxide radicals upon exposure to UV-B irradiation (Shaw et al. 2003), and the superoxide can be

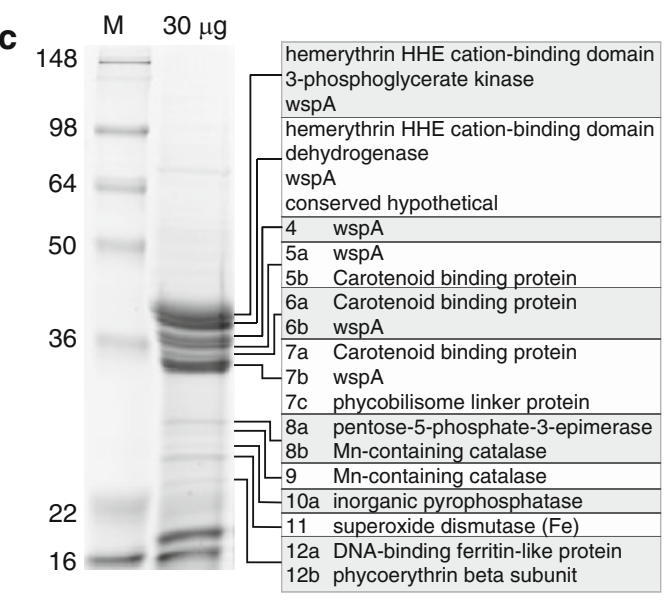

Other factors:

enzymatic activity

carotenoid binding protein

cell surface properties

intercellular communication
The rheology of the ECM2 is determined in part by the glycan and its associations with other matrix components. Glycan releases superoxide radicals that are quenched, in part, by the extracellular superoxide dismutase. (c) Isolation of the ECM proteins reveals isoforms of WspA, and several proteins that may have roles in ECM structure and function. scavenged by the superoxide dismutase (SOD) located within the glycan (Shirkey et al. 2000). This observation, as well as the identification of other molecules secreted from $N$. commune led to the hypothesis that the glycan provides the basic lattice of the extracellular matrix within which the central components of $\mathrm{WspA}$ and UV-absorbing pigments (mycospsorines, and scytonemin) are distributed (Fig. 18.9). With regard to the different levels of organization, when $N$. commune DRH1 is grown on calcium-supplemented media, the colonies take on a spherical shape and are brown pigmented because of scytonemin. Scytonemin is lipidsoluble and immobilized within the glycan, perhaps even polymerized following secretion from cells. WspA may play a role in modulating the higher order structure of the UV-absorbing pigments in the glycan matrix. It can be further hypothesized that a critical feature of these processes is the specific location of WspA, at the interface of a gel-sol transition boundary close to the cell surface (Fig. 18.7) (Hill et al. 1994a, b, 1997); see Sect. 18.1.3. The extremely hydrophilic nature of the N-terminus of WspA suggests a possible mechanistic basis for its orientation in this transition zone which, on the basis of the volatile nature of the latter during critical point drying (Fig. 18.4), was suggested to be the last repository of liquid, in otherwise desiccated colonies (Hill et al. 1997). 
Extracellular phosphatase activities were detected in 35 of 50 different cyanobacterial strains when growth media was assayed at pH 7.6 (Whitton et al. 1991). While it is generally considered that such activities are correlated with maintaining a phosphate supply (Whitton et al. 2005; Mateo et al. 2010), questions pertaining to export, enzymatic control, and half-life remain unanswered. Interestingly, the tyrosine phosphatase IphP of $N$. commune UTEX 584 (Potts et al. 1993) was secreted past the outer membrane of $E$. coli transformants. Thus one can hypothesize that phosphatase is also exported beyond the outer membrane of the host cyanobacterium.

The unicellular freshwater Synechocystis PCC 6803 was reported to produce at least seven secreted proteins (Sergeyenko and Los 2000), identified by N-terminal sequencing. Two of these, slr0168 and sll1891 (Nakao et al. 2010), are hypothetical proteins with no annotated conserved domains. S110044 is a hypothetical associated with phototaxis (Shin et al. 2008), and Slr0841 is currently listed as a periplasmic protein of unknown function with a weak association with a domain (META) that is associated with motility. S111694 is pilin polypeptide PilA1, slr0924 is a periplasmic protein of unknown function (Tic22), associated with the salt stress response (Fulda et al. 2006), and slr1855 is also a hypothetical protein with a strong association with the $N$-acyl-Dglucosamine 2-epimerase (AGE) domain (epimerization during biosynthesis of $\mathrm{N}$-acetylneuraminic acid).

A study of freshwater Oscillatoria sp. and Scytonema sp. found an extracellular phycoerythrin-like protein of approximately $250 \mathrm{kDa}$ that inhibited growth of two green algae, but not other cyanobacteria or eubacteria (Karseno et al. 2009). Data suggest that the extracellular pigment proteins were different from those found intracellularly, supporting the claim that the protein is secreted. This observation calls into question whether or not the presence of pigments in cyanobacterial culture supernatants is due solely to a cell lysis event. Gliding motility and cell-cell contacts in cyanobacteria are also associated with secreted and/or cell surface proteins. The surface of the gliding cyanobacterium Phormidium uncinatum contains fibrils on top of its S-layer surface (Smarda et al. 2002) that are comprised of the rodshaped $66 \mathrm{kDa}$ protein oscillin (Hoiczyk and Baumeister 1997). Evidence supports the role of this protein as a calcium-binding glycoprotein; strains that do not produce the protein lose motility. The marine Synechococcus WH8102 requires the S-layer glycoproteins SwmA (130 kDa) and SwmB (1.12 MDa) for non-flagellar movement (Brahamsha 1996; McCarren et al. 2005; McCarren and Brahamsha 2007, 2009), and Microcystis aeruginosa PCC 7806 appears to utilize an extracellular glycoprotein, MrpC $(15.5 \mathrm{kDa})$ as well as microvirin (12.2 kDa) for cell-cell contacts (Zilliges et al. 2008). The range of molecular weights in these proteins is rather intriguing. All of these proteins are thought to aggregate into larger quaternary structures, and thus it is possible that the resulting structures are all somewhat similar, only differing in the size of the repeat unit. Although little primary sequence homology exists between these polypeptides, this may be related to "self recognition" processes.

One of the more studied extracellular cyanobacterial proteins is cyanovirin-N (Boyd et al. 1997; Bewley et al. 1998; Botos et al. 2002). This small 11-kDa protein was first isolated from the aqueous cellular extract of laboratory-grown Nostoc ellipsosporum. Screening of this polypeptide classified it as an anti-HIV lectin due to its strong binding of the N-linked high-mannose oligosaccharide portion of the gp120 viral coat protein (Yang et al. 1999; Matei et al. 2008; Gronenborn 2009). This protein shares 33\% identity with a mannan-binding lectin (MVN) that is involved in cell-cell attachment in Microcystis aeruginosa (Kehr et al. 2006). The production of MVN is correlated with microcystin production, but microcystin production is not essential for its expression. Microcystins can control MVN binding partners, which were shown to be both in the sheath and the cell membrane; a scenario that permits cell aggregation.

Several other lectin-type molecules were also isolated from cyanobacteria, including scytovirin, the Microcystis viridis lectin (MVL), and Oscillatoria agardhii lectin (OAA) (Yamaguchi et al. 1999; Sato et al. 2007). While all of these polypeptides are the subject of studies related to their affinity to carbohydrates for viral therapy, work is expanding slowly with the aim to determine their roles in cyanobacterial physiology. Interestingly, a study on MVL revealed that the homodimer catalyzes the cleavage of chitotriose and chiototetraose to $N$-acetylglucosamine (GlcNAc) (Shahzad-UlHussan et al. 2009). NMR and mutagenesis studies revealed that the mechanism of hydrolysis occurred at a high mannose oligosaccharide binding site, suggesting that the polypeptide can bind one type of oligosaccharide as well as hydrolyze another. It is presumed that further study of cyanobacterial lectins will uncover additional dual roles. Note that the thermostable glycosidases from $N$. commune (Morsy et al. 2008) as well as the xylanohydrolase activities described by Potts (Hill et al. 1994a) may be related to these lectin-like/dualrole polypeptides.

\subsubsection{Non-reducing Oligosaccharides}

There are several reports that different species of filamentous, heterocyst-forming cyanobacteria produce a series of nonreducing oligosaccharides (Fischer et al. 2006; Pontis et al. 2007; Wieneke et al. 2007). Hot water extraction of whole cells was required to release these substances, calling into question if they are truly extracellular. Unpublished work 


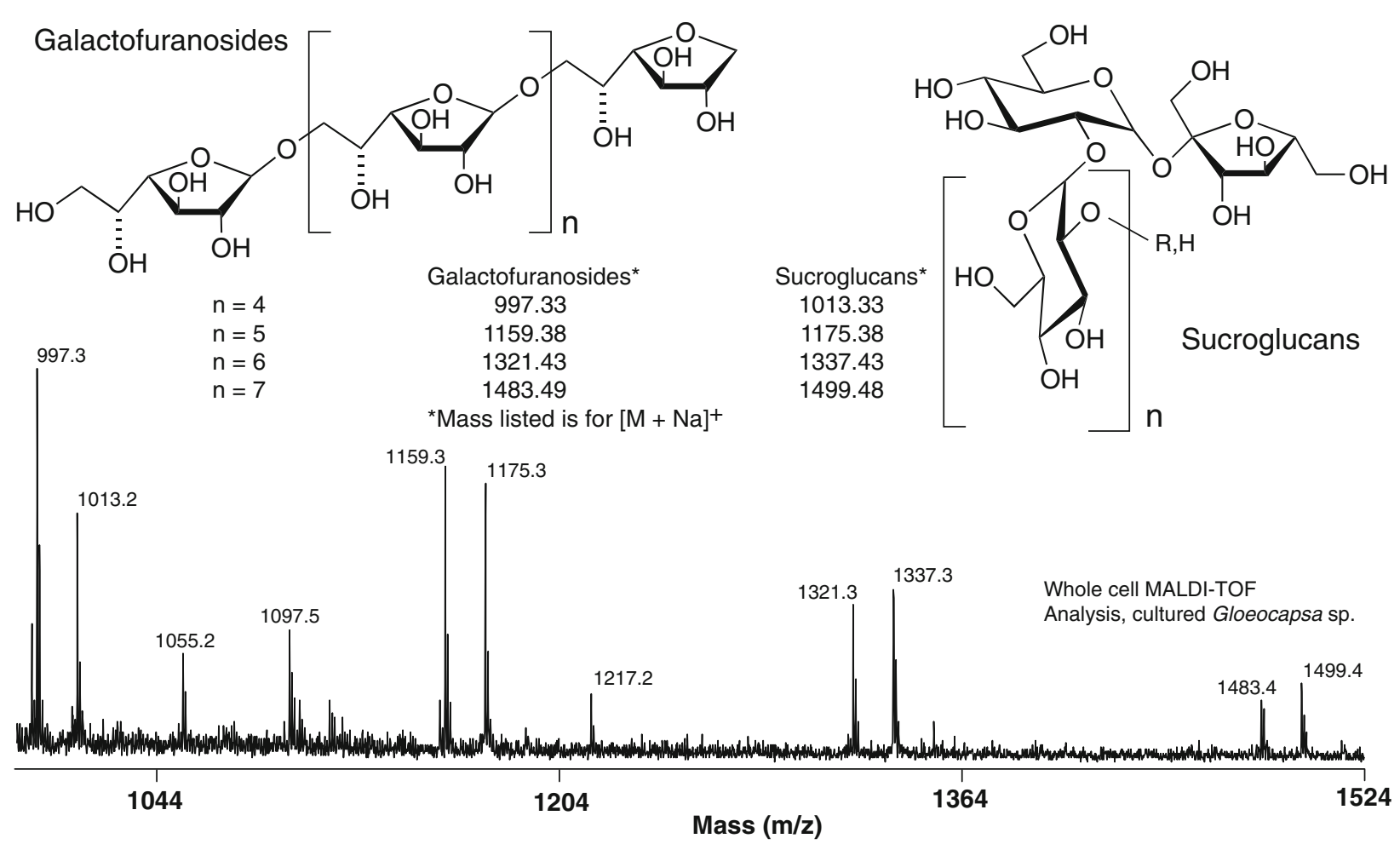

Fig. 18.8 Non-reducing oligosaccharides in cyanobacteria. Structures of the non-reducing galactofuranosides and sucroglucans are shown at the top. MALDI-TOF analysis of roof-isolated and subsequently cultured Gloeocapsa indicates that both oligosaccharides are present in this species.

from our laboratory utilizing whole cell MALDI-TOF analysis demonstrates that these compounds are released by the energy associated with the laser pulse (Fig. 18.8) suggesting that these substances may be at the surface of the cells or, at least in a position to be ionized. These structures may be more widespread than previously thought as they are also found in Gloeocapsa. In view of the discovery of glycosidase activity for lectins and the ability of lectins to bind specific glycan structures, it can be hypothesized that surface bound lectins adhere avidly to these oligosaccharides promoting a hydrophilic face to the extracellular environment, with extraction from whole cells requiring a hot water extraction. If these "lectins" also possess glycosidase activities (Shahzad-Ul-Hussan et al. 2009), the oligosaccharides could be released from desiccated cells as smaller oligo- or mono-saccharides during the resumption of metabolism. Such complexes may be part of the zone of "discontinuity" observed with desiccation-tolerant cyanobacteria (Fig. 18.3).

\subsubsection{EPS-Protein Complexes}

The previous discussions of extracellular proteins and the role of the EPS in spatial organization support the distinct possibility that EPS-protein complexes, whether covalent or non-covalent, are also important in ECM physiology. Phytoplankton-secreted polysaccharide-protein complexes of molecular weights greater than $1,000 \mathrm{kDa}$ can act as allelochemicals modulating phytoplankton communities (Yamasaki et al. 2009). Decho and coworkers provided data that further support the role of the EPS in $\mathrm{CaCO}_{3}$ deposition within cyanobacterial mats (Braissant et al. 2009). Such complexes may also be involved in mediating stromatolite formation and stabilization (Havemann and Foster 2008; Foster et al. 2009). Release of these substances was linked to a programmed cell death response in Trichodesmium (Berman-Frank et al. 2007).

Association between protein and polysaccharide can occur at the surface adjacent to the outer membrane or in the bulk ECM. Binding at the surface would be related to sheathtype EPS whereas bulk ECM binding would be associated with released polysaccharides. The release of transparent extracellular polysaccharides (TEP) from marine cyanobacteria may be due to production of proteases that not only cause cell death, but release the sheath constituents into the bulk solution as well. The change in cell density leads to settling of the cells, while the EPS materials remain in bulk solution until bound to suspended particle, which leads to deposition. Roles for these substances beyond lithification and carbon recycling are not explored to any great extent for the cyanobacteria. 


\subsubsection{Low Molecular Weight Substances (Secondary Metabolites)}

The total number of "secondary metabolites" produced by cyanobacteria is in the thousands, with many being present in the ECM; either released by living cells or from cell lysis of a subpopulation. Compounds range in size from the neurotoxin $\beta$-methylamino-L-alanine (BMAA) to cyclic peptides such as microviridin (Van Wagoner et al. 2007). Their roles in situ are not well understood, with hypotheses including defense strategies, gene regulation and cell-cell communication (Schatz et al. 2007).

Why so many small molecules? Such numbers are suggestive of a combinatorial library where each substance provides benefit to the organism for a particular environmental stress. Are there so many secondary metabolites because there are so many possible environmental perturbations? Is the library essentially a history of the organism with contributions from both mutational and gene transfer processes? This issue was the focus for the plant biology community for some time (Firn and Jones 2000, 2009; Fischbach and Clardy 2007) and is worth pondering from cyanobacterial and ecological perspectives.

When present as a member of a community, one can argue that four choices are possible: interaction, competition, neutrality or evasion. Interactions are positive as seen in cyanobacterial mats and stromatolites, and negative as exemplified by cyanobacterial phages or the toxicity of many cyanobacterial products towards humans. Neutrality is not truly an option as the footprint of any organism is presumably detected by another, especially when resources become scarce. Evasion requires movement and/or adoption of a state that does not permit detection. Based upon evidence presented to date, the best argument for cyanobacterial toxins is that they initially served a non-toxic, alternative purpose well before they impacted large-scale ecological niches (Leao et al. 2009, 2010) or considered contaminants in the human water supply (geosmin and 2-methylisoborneol) (Izaguirre et al. 1982; Agger et al. 2008).

As the cyanobacteria clearly predate eukaryotes, theories that support "secondary" metabolite production as a means to control grazing appear untenable in comparison to siderophoric activities and/or cell signaling activities (Rantala et al. 2004). Questions that arise are whether or not there are modifications to the molecule, if so are these related to random mutations within specific gene sequences, and whether or not the resulting product provides an advantage during subsequent stresses. This hypothesis would then require that variability of metabolite production in closely related strains would be the result of HGT, localized evolutionary pressures (resulting in gene loss), and potentially community-related signaling processes.

The most tenable hypothesis concerning the role of small extracellular molecules in cyanobacteria is that their initial advantage was for signaling purposes, such as PatS (Yoon and Golden 1998). Studies on microcystins in cyanobacterial populations in Antarctica does not provide much support for prevention of grazing and/or elimination of competing phytoplankton (Wood et al. 2008), as competition at these sites is minimal. Modulations of protease and phosphatase activities, whether intracellular or intracellular, are much stronger arguments. Such strategies may provide for adjustment to environmental stresses such as UV-light, changes in temperature, moisture, salinity, and the presence of phages.

Phages can be induced into a lytic phase, which results in lysis of the host cell, or a lysogenic phase, where the viral genome is maintained in the prophage state as the host grows and multiplies (Long et al. 2008). The prevailing thought with regards to the phage lifestyle is that that they can be both pathogenic (lytic) and mutualistic (lysogenic/prophage). Phages can deliver genes via horizontal gene transfer, which is a potential source of genes required to exit exposure to precarious environmental conditions that could compromise the viability of the organism or community (Lindell et al. 2004; Sullivan et al. 2006, 2009). Lysogeny has been correlated with conditions of low microbe abundance, and is considered an adaptive response to survive low host growth rates. A study with E. coli, P. aeruginosa and soil isolates containing cyanobacteria found a correlation between acylhomoserine lactones (autoinduction/quorum-sensing molecules) and phage production (Ghosh et al. 2009). Thus there may be a link between cyanobacterial-derived extracellular signalling molecules and phage physiology.

\subsection{Autoinduction Systems in Cyanobacteria}

Autoinduction is a process by which a compound released to the extracellular space modulates cellular behaviour (Nealson et al. 1970; Eberhard et al. 1981; Fuqua et al. 1994). Subsequently defined as quorum sensing (Fuqua et al. 1994), this messenger system is found in most Gram-negative bacteria (Whitehead et al. 2001; Waters and Bassler 2005; Dickschat 2010). Typically these molecules are detected when bacteria are grown to high cell density in the laboratory. An example of a field condition with high cell density would be a microbial mat or a stromatolite, or dense planktonic bloom; situations where cyanobacteria are present. While there are several types of quorum sensing molecules, acylhomoserine lactones are the most commonly studied, and can accumulate to $\mathrm{mM}$ concentrations in the extracellular space (Nadell et al. 2009).

Control of quorum sensing compound synthesis is of intense interest in the microbial community. In the strictest definition, current dogma posits that when the intracellular concentration of a QS molecule reaches a specific level, a change in gene expression occurs that leads to a change in 
community behaviour. Over 70 different species of bacteria are known to produce AHLs (Waters and Bassler 2005), and recent phylogenetic analyses suggest that the QS signaling pathway is present in 68 different bacterial genomes (Case et al. 2008), but not in the Archaea.

Cyanobacteria are observed to behave in a cooperative manner in community development, and hence it is logical to assume, that like most Gram-negative bacteria, they utilize sensing / autoinduction processes as well. The original definition of quorum sensing is that bacterial cells assess their environment by the production of autoinducer molecules that can modulate gene expression. This results in a group of cells acting as a behavioural unit (Hense et al. 2007). Known autoinducers include small peptides, a ribose derivative, or acyl homoserine lactones (AHLs). While QS has morphed over time to be considered a high cell density behaviour, QS processes are essentially sentinel systems invoked by single cells to query the local environment (Redfield 2002). Diffusion of the molecules away from the cell does not elicit a response. However, if the molecules remain in close proximity to the cell or a cluster of cells, their presence elicits a change in gene expression leading the production of additional secretory molecules such as degradative enzymes, siderophores, antibiotics or surfactants. This concept was extended recently to account for complex communities and the spatial distribution of cells within these communities and is termed efficiency sensing (Hense et al. 2007).

In the efficiency-sensing hypothesis, autoinducers are probes used to assess continually cell density, the spatial distribution of cells, and the mass transfer properties of the local environment. If autoinducer concentrations reach a specific threshold level, conditions are appropriate for the production of costlier extracellular effector molecules. By definition, this is not a cooperative or coordinated process; cells are acting individually but can act in coordinated fashion when neighboring cells have the same autoinducer system (Hense et al. 2007). In organisms that produce significant quantities of extracellular polysaccharides, clonal colonies can develop permitting group behaviour through positive feedback mechanisms. Such processes protect the developing colony through paracrine signaling while also promoting clonal diversity.

Boedicker et al. (2009) found that individual cells of $P$. aeruginosa confined to femtolitres of media can activate the quorum sensing pathway. Using transformed $E$. coli in a model biofilm (Timp et al. 2009), it was concluded that cellto-cell signaling is diffusion-controlled with a spatial distribution of autoinducers. Gantner et al. evaluated rhizobacteria on tomato and wheat roots and found that communication can occur in small groupings of cells and over ranges of up $78 \mu \mathrm{m}$ (Gantner et al. 2006). Such results suggest that autocrine and paracrine signalling occurring in bacteria is a consequence of individual cells, resulting in community-like responses.
Some cyanobacterial specialists have assumed that the traditional quorum sensing-type processes are not present (Haselkorn 2008). Hence the report of an acyl-homoserine lactone in Gloeothece PCC6909 was somewhat of a surprise (Sharif et al. 2008). This discovery supports the concept that some cyanobacteria can assess and respond to AHLs in their environment. (Romero et al. 2008, 2011). The recent demonstration of a $p$-coumaroyl homoserine lactone in photosynthetic bacteria (Rhodopseudomonas palustris, Bradyrhizobium sp. BTAi1) (Schaefer et al. 2008), the presence of extracellular "life cycle governing factors" (LCGFs) in N. punctiforme (Liaimer et al. 2011) as well as the results of others (Decho et al. 2009) suggest that the presence of sentinel sensing molecules in cyanobacteria deserves critical evaluation. Molecules such as geosmin and 2-methylisoborneol may indeed be part of the environmental sensing network in cyanobacteria.

\subsection{Oxidative Stress and Community Diversity}

The diversity of cyanobacterial communities suggests that mechanisms are in place to generate this diversity, with the overall goal of surviving in a natural environment. The "insurance hypothesis" for microbial systems posits that a RecA-mediated process leads to diversification, and these processes are enhanced in clonal biofilms (Boles et al. 2004, 2005). Such processes can lead to mutualistic behaviour where one variant can aid in the survival of another, eventually providing long-term stability of the community (Hillesland and Stahl 2010). The fact that clonal bacterial biofilms can generate measurable diversity within hours suggests a robust and rapidly mobilized mechanism. A more recent study of the insurance hypothesis led to the discovery that the mechanism is grounded in oxidative stress (Boles and Singh 2008). Endogenous oxidative stress leads to double strand DNA breaks, which when repaired, with some degree of inaccuracy, provides diversity. Subsequent environmental stresses result in the demise of some mutants and the advancement of others (Fig. 18.9).

The ECM of Nostoc commune contains a substantial quantity of superoxide dismutase (SOD), an enzyme that can be stored within the desiccated ECM for at least a decade; becoming active upon rehydration (Fig. 18.7) (Shirkey et al. 2000). The dismutation reaction forms both oxygen and hydrogen peroxide from the superoxide anion radical. While this dismutation reaction can occur non-enzymatically, SOD enzymes typically exhibit high turnover numbers, thereby keeping free radical concentrations low. When exposed to UV-light, the EPS of $N$. commune is a major source of free radicals (Shaw et al. 2003). Thus, while the EPS is protective under some conditions, it can be damaging under others, 


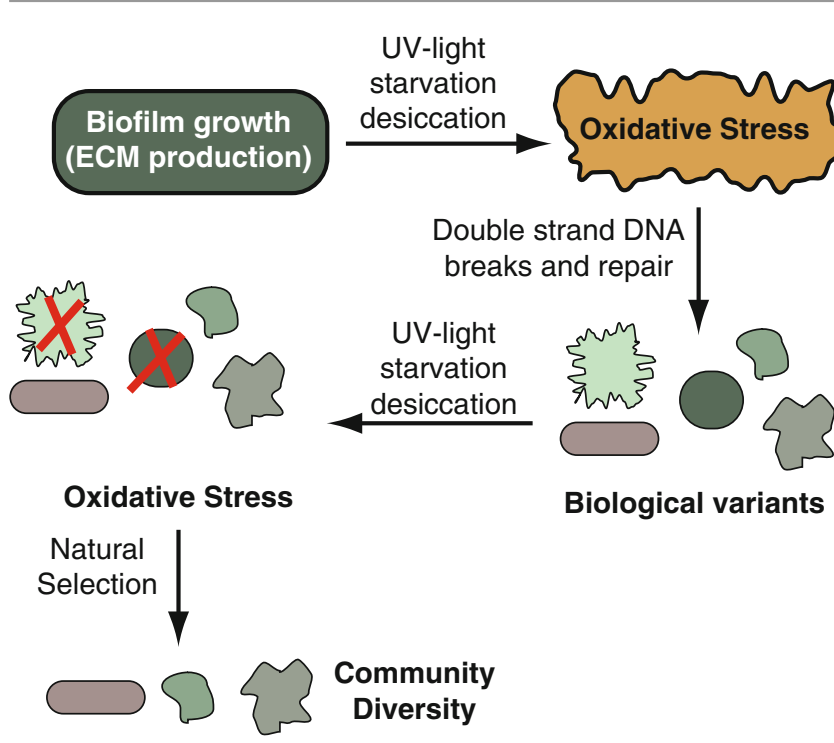

Fig. 18.9 The stochastic nature of microbial biodiversity. The Grampositive Bacillus subtilis can undergo phenotypic transformations that can lead to the cell types shown. Note that cyanobacteria have several analogous cell types including akinetes, hormogonia, vegetative cells (EPS producer) and heterocysts (EPS, death or surfactin producer?). Each of these cell types, upon exposure to oxidative stress, may respond differently, especially if their abilities to modulate oxidant levels differ. Thus the generation of biological variants can be likened to a "wheel of fortune" where each environmental perturbation can lead to a different variant (Concept adapted from Lopez and Kolter 2010).

with SOD providing free radical buffering capacity. While hydrogen peroxide can be quenched by catalases (note presence in the extracellular proteome of $N$. commune, Fig. 18.7), it could also be the molecule acting on DNA to provide oxidative stress, initiating double strand break repair processes and subsequent genome diversity.

Cell fate in a biofilm community will be dependent upon the location of a cell within the biofilm and the signals it receives from the environment. While much emphasis has been placed in intracellular signaling processes in cyanobacteria, evidence is clearly mounting that there is an extracellular component as well. The Gram-positive Bacillus subtilis has been shown to undergo phenotypic transformations that can lead to the cell types shown in Fig. 18.9 (Lopez et al. 2009a, b; Lopez and Kolter 2010). Note that cyanobacteria have several analogous cell types including akinetes (spore), hormogonia (motility), vegetative cells (EPS producer), necridia, and heterocysts (EPS, death or surfactin producer?). Each of these cell types, upon exposure to oxidative stress may respond differently, especially if their abilities to modulate oxidant levels are different. Thus the generation of biological variants can be likened to a "wheel of fate", where each environmental perturbation can lead to a different variant. Survival is thus dependent upon the ability of the variant to survive the next environmental stress (Fig. 18.10).

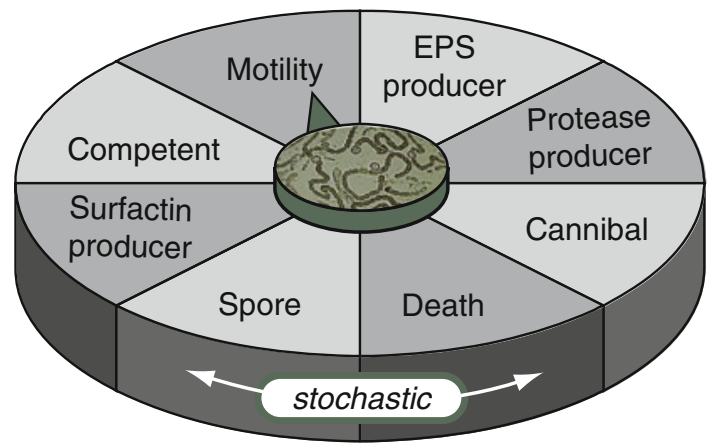

Fig. 18.10 Community diversity through oxidative stress. Biofilms are exposed to an environmental shift that causes oxidative stress. The ECM is both a source (bulk glycan) and dampener (UV photoprotective pigments and SOD) of oxidant levels. Oxidative stress leads to double strand DNA breaks and repair processes (RecA-mediated) lead to biological variants. These variants are exposed to additional stresses that select for the most robust. The net result is a more diverse community (Adapted from Boles and Singh 2008).

\subsection{Future Prospects}

The extracellular matrices of cyanobacteria are both complex and dynamic. Anionic polysaccharides provide a framework for the regio-deposition of an array of proteins, small molecules and potentially nucleic acids resulting in a fourdimensional matrix that permits survival under a particular set of environmental conditions. Adjustments to the ECM are continual and are hypothesized as providing the reagents necessary to yield genetic diversity.

Cyanobacteria can be found in all environments that receive light. Increases in the Earth's surface temperature are expected to favour cyanobacteria (Paerl and Huisman 2008) in aquatic ecosystems, potentially having dramatic effects on the safety of drinking water. Changes in rainfall and core land temperatures will also modulate cyanobacterial populations, although the net effect of increased temperatures and rising sea levels will probably result in more spatially-dependent changes in microbial populations/ecotypes (Green et al. 2008; Koeppel et al. 2008; Ward et al. 2008). Will terrestrial-, freshwater-, or marine-based changes in climate and carbon dioxide levels result in changes in cyanobacterial communities? Efforts to understand cyanobacterial physiology are important for understanding the interactive roles cyanobacteria play in localized as well as global processes.

Over 75 cyanobacterial genomic and metagenomic projects are completed or are currently underway. This number reflects the biological and ecological importance of these microbes. However, considering the efforts underway at the genomic level, it is extremely surprising to see that cyanobacterial "metabolomic" projects initially appeared in the literature only recently (Eisenhut et al. 2008; Wase and Wright 2008; Krall et al. 2009; Bennette et al. 2011). The cyanobacterial 
research community would benefit greatly from datasets characterizing extracellular metabolite pools and how they change upon environmental stress and/or genetic perturbation (Baran et al. 2010, 2011). Even if we confine our discussion of cyanobacteria to just those species presently available from culture collections, we have an exceedingly poor understanding of the breadth and diversity of molecules within these collections and how they change as the result of culture conditions. Such baseline evaluation is critical for assessing chemotypic changes associated with environmental and/or genetic inputs. Profiling efforts that initially provide broad screens will provide the general overview required for quantitative studies that target specific metabolites, processes, and/or cell types. Such datasets are crucial to rationally directing molecular biology toward new and important genes and enzymatic processes (Balskus and Walsh 2009, 2010; Jones et al. 2009, 2010; Leikoski et al. 2009, 2010; Sivonen et al. 2010; Spence et al. 2012).

While studies in the evolutionary pressures and processes continue to provide insights into cyanobacterial history and diversity, such efforts can only suggest a physiological understanding of why a particular ecotype is advantageous over another. Metagenomic screens cannot provide direct insight into survival mechanisms or community behaviour either. Evaluation of stress responses in microbial communities in real time requires interrogating the metagenomic outputs: proteins, secondary metabolites and polysaccharides. These molecules have a much higher "resolving power" than nucleic acids; hence the emphasis on biomarkers in biomedical research. Analysis of the molecular species (glycans, small molecules, and proteins) placed outside the cyanobacterial cell will provide the information necessary to test the insurance hypothesis and if indeed oxidative stress is the source of genetic diversity. Evaluation of cyanobacterial growth at the level of extracellular molecular species will provide new insights into the species/ecotype concept, lead us to a better understanding of the core cyanobacterial genes, offer fundamental units (molecules) of cyanobacterial diversity and shed additional light on how/why biosynthetic pathways diverge.

\section{References}

Agger SA, Lopez-Gallego F, Hoye TR, Schmidt-Dannert C (2008) Identification of sesquiterpene synthases from Nostoc punctiforme PCC 73102 and Nostoc sp. strain PCC 7120. J Bacteriol 190: 6084-6096

Alberts B, Johnson A, Lewis J, Raff M, Roberts K, Walter P (2008) Molecular biology of the cell, 4th edn. Garland Science, New York, $1359 \mathrm{pp}$

Allesen-Holm M, Barken KB, Yang L, Klausen M, Webb JS, Kjelleberg S et al (2006) A characterization of DNA release in Pseudomonas aeruginosa cultures and biofilms. Mol Microbiol 59:1114-1128
Balskus EP, Walsh CT (2009) An enzymatic cyclopentyl[b]indole formation involved in scytonemin biosynthesis. J Am Chem Soc 131:14648-14649

Balskus EP, Walsh CT (2010) The genetic and molecular basis for sunscreen biosynthesis in cyanobacteria. Science 329:1653-1656

Baran R, Bowen BP, Bouskill NJ, Brodie EL, Yannone SM, Northen TR (2010) Metabolite identification in Synechococcus sp. PCC 7002 using untargeted stable isotope assisted metabolite profiling. Anal Chem 82:9034-9042

Baran R, Bowen BP, Northen TR (2011) Untargeted metabolic footprinting reveals a surprising breadth of metabolite uptake and release by Synechococcus sp. PCC 7002. Mol Biosyst 7:3200-3206

Barberousse H, Ruiz G, Gloaguen V, Lombardo RJ, Djediat C, Mascarell $\mathrm{G}$ et al (2006) Capsular polysaccharides secreted by building facade colonisers: characterisation and adsorption to surfaces. Biofouling 22:361-370

Battistuzzi FU, Hedges SB (2009) A major clade of prokaryotes with ancient adaptations to life on land. Mol Biol Evol 26:335-343

Bennette NB, Eng JF, Dismukes GC (2011) An LC-MS-based chemical and analytical method for targeted metabolite quantification in the model cyanobacterium Synechococcus sp. PCC 7002. Anal Chem 83:3808-3816

Berman-Frank I, Rosenberg G, Levitan O, Haramaty L, Mari X (2007) Coupling between autocatalytic cell death and transparent exopolymeric particle production in the marine cyanobacterium Trichodesmium. Environ Microbiol 9:1415-1422

Bewley CA, Gustafson KR, Boyd MR, Covell DG, Bax A, Clore GM et al (1998) Solution structure of cyanovirin-N, a potent HIVinactivating protein. Nat Struct Biol 5:571-578

Boedicker JQ, Vincent ME, Ismagilov RF (2009) Microfluidic confinement of single cells of bacteria in small volumes initiates high-density behavior of quorum sensing and growth and reveals its variability. Angew Chem Int Ed Engl 48:5908-5911

Bohm GA, Pfleiderer W, Boger P, Scherer S (1995) Structure of a novel oligosaccharide-mycosporine amino acid ultraviolet A/B sunscreen from the terrestrial cyanobacterium Nostoc commune. J Biol Chem 270:8536-8539

Boles BR, Singh PK (2008) Endogenous oxidative stress produces diversity and adaptability in biofilm communities. Proc Natl Acad Sci USA 105:12503-12508

Boles BR, Thoendel M, Singh PK (2004) Self-generated diversity produces "insurance effects" in biofilm communities. Proc Natl Acad Sci USA 101:16630-16635

Boles BR, Thoendel M, Singh PK (2005) Genetic variation in biofilms and the insurance effects of diversity. Microbiology 151:2816-2818

Botos I, O'Keefe BR, Shenoy SR, Cartner LK, Ratner DM, Seeberger $\mathrm{PH}$ et al (2002) Structures of the complexes of a potent anti-HIV protein cyanovirin- $\mathrm{N}$ and high mannose oligosaccharides. J Biol Chem 277:34336-34342

Boyd MR, Gustafson KR, McMahon JB, Shoemaker RH, Okeefe BR, Mori T et al (1997) Discovery of cyanovirin-N, a novel human immunodeficiency virus-inactivating protein that binds viral surface envelope glycoprotein gp120: potential applications to microbicide development. Antimicrob Agents Chemother 41:1521-1530

Brahamsha B (1996) An abundant cell-surface polypeptide is required for swimming by the nonflagellated marine cyanobacterium Synechococcus. Proc Natl Acad Sci USA 93:6504-6509

Braissant O, Decho AW, Przekop KM, Gallagher KL, Glunk C, Dupraz C et al (2009) Characteristics and turnover of exopolymeric substances in a hypersaline microbial mat. FEMS Microbiol Ecol 67:293-307

Case RJ, Labbate M, Kjelleberg S (2008) AHL-driven quorum-sensing circuits: their frequency and function among the Proteobacteria. ISME J 2:345-349

Cates ME, Marenduzzo D, Pagonabarraga I, Tailleur J (2010) Arrested phase separation in reproducing bacteria creates a generic route to pattern formation. Proc Natl Acad Sci USA 107:11715-11720 
Chen LZ, Wang GH, Hong S, Liu A, Li C, Liu YD (2009) UV-Binduced oxidative damage and protective role of exopolysaccharides in desert cyanobacterium Microcoleus vaginatus. J Integr Plant Biol 51:194-200

Costerton WJ (2004) A short history of the development of the biofilm concept. In: Ghannoum M, O'Toole GA (eds) Microbial biofilms. ASM Press, Washington, DC, pp 4-19

Cuthbertson L, Mainprize IL, Naismith JH, Whitfield C (2009) Pivotal roles of the outer membrane polysaccharide export and polysaccharide copolymerase protein families in export of extracellular polysaccharides in gram-negative bacteria. Microbiol Mol Biol Rev 73:155-177

De Philippis R, Vincenzini M (1998) Exocellular polysaccharides from cyanobacteria and their possible applications. FEMS Microbiol Rev $22: 151-175$

Decho AW, Visscher PT, Ferry J, Kawaguchi T, He L, Przekop KM et al (2009) Autoinducers extracted from microbial mats reveal a surprising diversity of $\mathrm{N}$-acylhomoserine lactones (AHLs) and abundance changes that may relate to diel $\mathrm{pH}$. Environ Microbiol 11:409-420

Dell' Anno A, Danovaro R (2005) Extracellular DNA plays a key role in deep-sea ecosystem functioning. Science 309:2179-2179

Dickschat JS (2010) Quorum sensing and bacterial biofilms. Nat Prod Rep 27:343-369

Dittrich M, Sibler S (2005) Cell surface groups of two picocyanobacteria strains studied by zeta potential investigations, potentiometric titration, and infrared spectroscopy. J Colloid Interface Sci 286 487-495

Eberhard A, Burlingame AL, Eberhard C, Kenyon GL, Nealson KH, Oppenheimer NJ (1981) Structural identification of autoinducer of Photobacterium fischeri luciferase. Biochemistry 20:2444-2449

Ehling-Schulz M, Schulz S, Wait R, Gorg A, Scherer S (2002) The UV-B stimulon of the terrestrial cyanobacterium Nostoc commune comprises early shock proteins and late acclimation proteins. Mol Microbiol 46:827-843

Eisenhut M, Huege J, Schwarz D, Bauwe H, Kopka J, Hagemann M (2008) Metabolome phenotyping of inorganic carbon limitation in cells of the wild type and photorespiratory mutants of the cyanobacterium Synechocystis sp. strain PCC 6803. Plant Physiol 148:2109-2120

Firn RD, Jones CG (2000) The evolution of secondary metabolism - a unifying model. Mol Microbiol 37:989-994

Firn RD, Jones CG (2009) A Darwinian view of metabolism: molecular properties determine fitness. J Exp Bot 60:719-726

Fischbach MA, Clardy J (2007) One pathway, many products. Nat Chem Biol 3:353-355

Fischer D, Geyer A, Loos E (2006) Occurrence of glucosylsucrose alpha-D-glucopyranosyl-(1->2)-alpha-D-glucopyranosyl-(1->2)beta-D-fructofuranoside and glucosylated homologues in cyanobacteria - Structural properties, cellular contents and possible function as thermoprotectants. FEBS J 273:137-149

Flores E, Herrero A (2010) Compartmentalized function through cell differentiation in filamentous cyanobacteria. Nat Rev Microbiol $8: 39-50$

Foster JS, Green SJ, Ahrendt SR, Golubic S, Reid RP, Hetherington KL et al (2009) Molecular and morphological characterization of cyanobacterial diversity in the stromatolites of Highborne Cay, Bahamas. ISME J 3:573-587

Fulda S, Mikkat S, Huang F, Huckauf J, Marin K, Norling B et al (2006) Proteome analysis of salt stress response in the cyanobacterium Synechocystis sp strain PCC 6803. Proteomics 6:2733-2745

Fuqua WC, Winans SC, Greenberg EP (1994) Quorum sensing in bacteria: the LuxR-LuxI family of cell density-responsive transcriptional regulators. J Bacteriol 176:269-275

Gantner S, Schmid M, Durr C, Schuhegger R, Steidle A, Hutzler P et al (2006) In situ quantitation of the spatial scale of calling distances and population density-independent $\mathrm{N}$-acylhomoserine lactone- mediated communication by rhizobacteria colonized on plant roots. FEMS Microbiol Ecol 56:188-194

Garcia-Pichel F, Pringault O (2001) Microbiology - cyanobacteria track water in desert soils. Nature 413:380-381

Garcia-Pichel F, Wojciechowski MF (2009) The evolution of a capacity to build supra-cellular ropes enabled filamentous cyanobacteria to colonize highly erodible substrates. PLoS One 4:e7801

Geitler L (1932) Cyanophyceae. Rabenhorst's Krytogamen-Flora von Deutschland, Österreich und der Schweiz 14. Akademische Verlagsgesellschaft, Leipzig, 1196 pp

Ghosh D, Roy K, Williamson KE, Srinivasiah S, Wommack KE, Radosevich M (2009) Acyl-homoserine lactones can induce virus production in lysogenic bacteria: an alternative paradigm for prophage induction. Appl Environ Microbiol 75:7142-7152

Gorbushina AA (2007) Life on the rocks. Environ Microbiol 9:1613-1631

Gorbushina AA, Broughton WJ (2009) Microbiology of the atmosphere-rock interface: how biological interactions and physical stresses modulate a sophisticated microbial ecosystem. Annu Rev Microbiol 63:431-450

Green JL, Bohannan BJ, Whitaker RJ (2008) Microbial biogeography: from taxonomy to traits. Science 320:1039-1043

Gronenborn AM (2009) Protein acrobatics in pairs - dimerization via domain swapping. Curr Opin Struct Biol 19:39-49

Gupta RS (2009) Protein signatures (molecular synapomorphies) that are distinctive characteristics of the major cyanobacterial clades. Int J Syst Evol Microbiol 59:2510-2526

Gupta RS, Mathews DW (2010) Signature proteins for the major clades of cyanobacteria. BMC Evol Biol 10:24

Harmsen M, Lappann M, Knochel S, Molin S (2010) Role of extracellular DNA during biofilm formation by Listeria monocytogenes. Appl Environ Microbiol 76:2271-2279

Haselkorn R (2008) Cell-cell communication in filamentous cyanobacteria. Mol Microbiol 70:783-785

Havemann SA, Foster JS (2008) Comparative characterization of the microbial diversities of an artificial microbialite model and a natural stromatolite. Appl Environ Microbiol 74:7410-7421

Helm RF, Huang Z, Edwards D, Leeson H, Peery W, Potts M (2000) Structural characterization of the released polysaccharide of desiccation-tolerant Nostoc commune DRH-1. J Bacteriol 182:974-982

Hense BA, Kuttler C, Muller J, Rothballer M, Hartmann A, Kreft J-U (2007) Does efficiency sensing unify diffusion and quorum sensing? Nat Rev Microbiol 5:230-239

Hill DR, Hladun SL, Scherer S, Potts M (1994a) Water-stress proteins of Nostoc commune (Cyanobacteria) are secreted with UV-A/B-absorbing pigments and associate with 1,4-beta-D-xylanohydrolase activity. J Biol Chem 269:7726-7734

Hill DR, Peat A, Potts M (1994b) Biochemistry and structure of the glycan secreted by desiccation-tolerant Nostoc commune (Cyanobacteria). Protoplasma 182:126-148

Hill DR, Keenan TW, Helm RF, Potts M, Crowe LM, Crowe JH (1997) Extracellular polysaccharide of Nostoc commune (cyanobacteria) inhibits fusion of membrane vesicles during desiccation. J Appl Phycol 9:237-248

Hillesland KL, Stahl DA (2010) Rapid evolution of stability and productivity at the origin of a microbial mutualism. Proc Natl Acad Sci USA 107:2124-2129

Hoiczyk E, Baumeister W (1997) Oscillin, an extracellular, Ca2+binding glycoprotein essential for the gliding motility of cyanobacteria. Mol Microbiol 26:699-708

Hoiczyk E, Hansel A (2000) Cyanobacterial cell walls: news from an unusual prokaryotic envelope. J Bacteriol 182:1191-1199

Izaguirre G, Hwang CJ, Krasner SW, McGuire MJ (1982) Geosmin and 2-methylisoborneol from cyanobacteria in three water supply systems. Appl Environ Microbiol 43:708-714 
Jones AC, Gu L, Sorrels CM, Sherman DH, Gerwick WH (2009) New tricks from ancient algae: natural products biosynthesis in marine cyanobacteria. Curr Opin Chem Biol 13:216-223

Jones AC, Monroe EA, Eisman EB, Gerwick L, Sherman DH, Gerwick WH (2010) The unique mechanistic transformations involved in the biosynthesis of modular natural products from marine cyanobacteria. Nat Prod Rep 27:1048-1065

Karatan E, Watnick P (2009) Signals, regulatory networks, and materials that build and break bacterial biofilms. Microbiol Mol Biol Rev 73:310-347

Karseno HK, Bamba T, Dwi S, Mahakhant A, Yoshikawa T et al (2009) Extracellular phycoerythrin-like protein released by freshwater cyanobacteria Oscillatoria and Scytonema sp. Biotechnol Lett 31:999-1003

Kehr JC, Zilliges Y, Springer A, Disney MD, Ratner DD, Bouchier C et al (2006) A mannan binding lectin is involved in cell-cell attachment in a toxic strain of Microcystis aeruginosa. Mol Microbiol 59:893-906

Koeppel A, Perry EB, Sikorski J, Krizanc D, Warner A, Ward DM et al (2008) Identifying the fundamental units of bacterial diversity: a paradigm shift to incorporate ecology into bacterial systematics. Proc Natl Acad Sci USA 105:2504-2509

Krall L, Huege J, Catchpole G, Steinhauser D, Willmitzer L (2009) Assessment of sampling strategies for gas chromatography-mass spectrometry (GC-MS) based metabolomics of cyanobacteria. J Chromatogr B Anal Technol Biomed Life Sci 877:2952-2960

Kumar KV, Kumaran A (2005) Voronoi cell volume distribution and configuration entropy of hard-spheres. J Chem Phys 123:114501

Lake JA (2009) Evidence for an early prokaryotic endosymbiosis. Nature 460:967-971

Lappann M, Claus H, van Alen T, Harmsen M, Elias J, Molin S et al (2010) A dual role of extracellular DNA during biofilm formation of Neisseria meningitidis. Mol Microbiol 75:1355-1371

Leao PN, Vasconcelos MT, Vasconcelos VM (2009) Allelopathy in freshwater cyanobacteria. Crit Rev Microbiol 35:271-282

Leao PN, Pereira AR, Liu WT, Ng J, Pevzner PA, Dorrestein PC, Konig GM, Vasconcelos VM, Gerwick WH (2010) Synergistic allelochemicals from a freshwater cyanobacterium. Proc Natl Acad Sci USA 107:11183-11188

Lehner J, Zhang Y, Berendt S, Rasse TM, Forchhammer K, Maldener I (2011) The morphogene AmiC2 is pivotal for multicellular development in the cyanobacterium Nostoc punctiforme. Mol Microbiol 79:1655-1669

Leikoski N, Fewer DP, Sivonen K (2009) Widespread occurrence and lateral transfer of the cyanobactin biosynthesis gene cluster in cyanobacteria. Appl Environ Microbiol 75:853-857

Leikoski N, Fewer DP, Jokela J, Wahlsten M, Rouhiainen L, Sivonen K (2010) Highly diverse cyanobactins in strains of the genus Anabaena. Appl Environ Microbiol 76:701-709

Liaimer A, Jenke-Kodama H, Ishida K, Hinrichs K, Stangeland J, Hertweck C, Dittmann E (2011) A polyketide interferes with cellular differentiation in the symbiotic cyanobacterium Nostoc punctiforme. Environ Microbiol Rep 3: 550-558

Lindell D, Sullivan MB, Johnson ZI, Tolonen AC, Rohwer F, Chisholm SW (2004) Transfer of photosynthesis genes to and from Prochlorococcus viruses. Proc Natl Acad Sci USA 101: 11013-11018

Long A, McDaniel LD, Mobberley J, Paul JH (2008) Comparison of lysogeny (prophage induction) in heterotrophic bacterial and Synechococcus populations in the Gulf of Mexico and Mississippi River plume. ISME J 2:132-144

Lopez D, Kolter R (2010) Extracellular signals that define distinct and coexisting cell fates in Bacillus subtilis. FEMS Microbiol Rev 34:134-149

Lopez D, Vlamakis H, Kolter R (2009a) Generation of multiple cell types in Bacillus subtilis. FEMS Microbiol Rev 33:152-163
Lopez D, Vlamakis H, Losick R, Kolter R (2009b) Paracrine signaling in a bacterium. Genes Dev 23:1631-1638

Macedo MF, Miller AZ, Dionisio A, Saiz-Jimenez C (2009) Biodiversity of cyanobacteria and green algae on monuments in the Mediterranean Basin: an overview. Microbiology 155:3476-3490

Marenduzzo D, Finan K, Cook PR (2006) The depletion attraction: an underappreciated force driving cellular organization. J Cell Biol 175:681-686

Martinez RE, Pokrovsky OS, Schott J, Oelkers EH (2008) Surface charge and zeta-potential of metabolically active and dead cyanobacteria. J Colloid Interface Sci 323:317-325

Martinez RE, Gardes E, Pokrovsky OS, Schott J, Oelkers EH (2010) Do photosynthetic bacteria have a protective mechanism against carbonate precipitation at their surfaces? Geochim Cosmochim Acta 74:1329-1337

Matei E, Furey W, Gronenborn AM (2008) Solution and crystal structures of a sugar binding site mutant of cyanovirin-N: no evidence of domain swapping. Structure 16:1183-1194

Mateo P, Berrendero E, Perona E, Loza V, Whitton BA (2010) Phosphatase activities of cyanobacteria as indicators of nutrient status in a Pyrenees river. Hydrobiologia 652:255-268

McCarren J, Brahamsha B (2007) SwmB, a 1.12-megadalton protein that is required for nonflagellar swimming motility in Synechococcus. J Bacteriol 189:1158-1162

McCarren J, Brahamsha B (2009) Swimming motility mutants of marine Synechococcus affected in production and localization of the S-Layer protein SwmA. J Bacteriol 191:1111-1114

McCarren J, Heuser J, Roth R, Yamada N, Martone M, Brahamsha B (2005) Inactivation of swmA results in the loss of an outer cell layer in a swimming Synechococcus strain. J Bacteriol 187:224-230

Morsy FM, Kuzuha S, Takani Y, Sakamoto T (2008) Novel thermostable glycosidases in the extracellular matrix of the terrestrial cyanobacterium Nostoc commune. J Gen Appl Microbiol 54:243-252

Morvan H, Gloaguen V, Vebret L, Joset F, Hoffmann L (1997) Structurefunction investigations on capsular polymers as a necessary step for new biotechnological applications: the case of the cyanobacterium Mastigocladus laminosus. Plant Physiol Biochem 35:671-683

Nadell CD, Xavier JB, Foster KR (2009) The sociobiology of biofilms. FEMS Microbiol Rev 33:206-224

Nakao M, Okamoto S, Kohara M, Fujishiro T, Fujisawa T, Sato S et al (2010) CyanoBase: the cyanobacteria genome database update 2010. Nucleic Acids Res 38:D379-D381

Nealson KH, Platt T, Hastings JW (1970) Cellular control of the synthesis and activity of the Bacterial luminescent system. J Bacteriol 104:313-322

OED (2009) Oxford english dictionary. Oxford University Press, Oxford

Paerl HW, Huisman J (2008) Climate. Blooms like it hot. Science 320:57-58

Paerl HW, Steppe TF, Buchan KC, Potts M (2003) Hypersaline cyanobacterial mats as indicators of elevated tropical hurricane activity and associated climate change. Ambio 32:87-90

Peat A, Powell N, Potts M (1988) Ultrastructural analysis of the rehydration of desiccated Nostoc commune Hun (Cyanobacteria) with particular reference to the immunolabelling of NifH. Protoplasma 146:72-80

Pereira S, Zille A, Micheletti E, Moradas-Ferreira P, De Philippis R, Tamagnini P (2009) Complexity of cyanobacterial exopolysaccharides: composition, structures, inducing factors and putative genes involved in their biosynthesis and assembly. FEMS Microbiol Rev 33:917-941

Pontis HG, Vargas WA, Salerno GL (2007) Structural characterization of the members of a polymer series, compatible solutes in Anabaena cells exposed to salt stress. Plant Sci 172:29-35

Potts M (1980) Blue-green-algae (Cyanophyta) in marine coastal environments of the Sinai peninsula: distribution, zonation, stratification, and taxonomic diversity. Phycologia 19:60-73

Potts M (1997) Etymology of the genus name Nostoc (cyanobacteria). Int J Syst Bacteriol 47:584 
Potts M, Sun H, Mockaitis K, Kennelly PJ, Reed D, Tonks NK (1993) A protein-tyrosine/serine phosphatase encoded by the genome of the cyanobacterium Nostoc commune UTEX 584. J Biol Chem 268:7632-7635

Potts M (2000) Nostoc. In: Whitton BA, Potts M (eds) The ecology of cyanobacteria. Their diversity in time and space. Kluwer Academic Publishers, Dordrecht, pp 465-504, 669 pp

Rantala A, Fewer DP, Hisbergues M, Rouhiainen L, Vaitomaa J, Börner T (2004) Phylogenetic evidence for the early evolution of microcystin synthesis. Proc Natl Acad Sci USA 101:568-573

Read N, Connell S, Adams DG (2007) Nanoscale visualization of a fibrillar array in the cell wall of filamentous cyanobacteria and its implications for gliding motility. J Bacteriol 189:7361-7366

Redfield RJ (2002) Is quorum sensing a side effect of diffusion sensing? Trends Microbiol 10:365-370

Rippka R, Deruelles J, Waterbury JB, Herdman M, Stanier RY (1979) Generic assignments, strain histories and properties of pure cultures of cyanobacteria. J Gen Microbiol 111:1-61

Romero M, Diggle SP, Heeb S, Camara M, Otero A (2008) Quorum quenching activity in Anabaena sp. PCC 7120: identification of AiiC, a novel AHL-acylase. FEMS Microbiol Lett 280:73-80

Romero M, Muro-Pastor AM, Otero A (2011) Quorum sensing $N$-acylhomoserine lactone signals affect nitrogen fixation in the cyanobacterium Anabaena sp. PCC7120. FEMS Microbiol Lett 315:101-108

Rycroft CH, Grest GS, Landry JW, Bazant MZ (2006) Analysis of granular flow in a pebble-bed nuclear reactor. Phys Rev E 74:16

Sanchez-Baracaldo P, Hayes PK, Blank CE (2005) Morphological and habitat evolution in the Cyanobacteria using a compartmentalization approach. Geobiology 3:145-165

Sato Y, Okuyama S, Hori K (2007) Primary structure and carbohydrate binding specificity of a potent anti-HIV lectin isolated from the filamentous cyanobacterium Oscillatoria agardhii. J Biol Chem 282:11021-11029

Scanlan DJ, Carr NG (1988) Extracellular proteins. In: Packer L, Glazer AN (eds) Methods in enzymology, vol 167. Academic, San Diego, pp 599-605

Scanlan DJ, Ostrowski M, Mazard S, Dufresne A, Garczarek L, Hess WR, Post AF, Hagemann M, Paulsen I, Partensky F (2009) Ecological genomics of marine picocyanobacteria. Microbiol Mol Biol Rev 73:249-299

Schaefer AL, Greenberg EP, Oliver CM, Oda Y, Huang JJ, Bittan-Banin G, Peres GM, Schmidt S, Juhaszova K, Sufrin JR et al (2008) A new class of homoserine lactone quorum-sensing signals. Nature 454:595-599

Schatz D, Keren Y, Vardi A, Sukenik A, Carmeli S, Börner T, Dittmann E, Kaplan A et al (2007) Towards clarification of the biological role of microcystins, a family of cyanobacterial toxins. Environ Microbiol 9:965-970

Schaudinn C, Stoodley P, Kainović A, O'Keeffe T, Costerton B, Robinson D, Baum D, Ehrlich G, Webster P (2007) Bacterial biofilms, other structures seen as mainstream concepts. Microbe 2:231-237

Scherer S, Potts M (1989) Novel water-stress protein from a desiccationtolerant cyanobacterium - purification and partial characterization. J Biol Chem 264:12546-12553

Schirrmeister BE, Antonelli A, Bagheri HC (2011) The origin of multicellularity in cyanobacteria. BMC Evol Biol 11:45

Sergeyenko TV, Los DA (2000) Identification of secreted proteins of the cyanobacterium Synechocystis sp strain PCC 6803. FEMS Microbiol Lett 193:213-216

Shahzad-Ul-Hussan S, Cai ML, Bewley CA (2009) Unprecedented glycosidase activity at a lectin carbohydrate-binding site exemplified by the cyanobacterial lectin MVL. J Am Chem Soc 131:16500-16508

Sharif DI, Gallon J, Smith CJ, Dudley E (2008) Quorum sensing in cyanobacteria: N-octanoyl-homoserine lactone release and response, by the epilithic colonial cyanobacterium Gloeothece PCC6909. ISME J 2:1171-1182
Shaw E, Hill DR, Brittain N, Wright DJ, Tauber U, Marand H et al (2003) Unusual water flux in the extracellular polysaccharide of the cyanobacterium Nostoc commune. Appl Environ Microbiol 69:5679-5684

Shi T, Falkowski PG (2008) Genome evolution in cyanobacteria: the stable core and the variable shell. Proc Natl Acad Sci USA 105:2510-2515

Shin BJ, Oh J, Kang S, Chung YH, Park YM, Kim YH, Kim S, Bhak J, Choi JS (2008) Cyanobacterial hybrid kinase Sll0043 regulates phototaxis by suppressing pilin and twitching motility protein. J Microbiol 46:300-308

Shirkey B, Kovarcik DP, Wright DJ, Wilmoth G, Prickett TF, Helm RF et al (2000) Active Fe-containing superoxide dismutase and abundant sodF mRNA in Nostoc commune (cyanobacteria) after years of desiccation. J Bacteriol 182:189-197

Sivonen K, Leikoski N, Fewer DP, Jokela J (2010) Cyanobactinsribosomal cyclic peptides produced by cyanobacteria. Appl Microbiol Biotechnol 86:1213-1225

Smarda J, Smajs D, Komrska J, Krzyzanek V (2002) S-layers on cell walls of cyanobacteria. Micron 33:257-277

Spence E, Dunlap WC, Shick JM, Long PF (2012) Redundant pathways of sunscreen biosynthesis in a cyanobacterium. Chembiochem 13:531-533

Steinberger RE, Holden PA (2005) Extracellular DNA in single- and multiple-species unsaturated biofilms. Appl Environ Microbiol 71:5404-5410

Stewart PS, Franklin MJ (2008) Physiological heterogeneity in biofilms. Nat Rev Microbiol 6:199-210

Stoodley P, Sauer K, Davies DG, Costerton JW (2002) Biofilms as complex differentiated communities. Annu Rev Microbiol 56:187-209

Sullivan MB, Lindell D, Lee JA, Thompson LR, Bielawski JP, Chisholm SW (2006) Prevalence and evolution of core photosystem II genes in marine cyanobacterial viruses and their hosts. PLoS Biol 4:e234

Sullivan MB, Krastins B, Hughes JL, Kelly L, Chase M, Sarracino D et al (2009) The genome and structural proteome of an ocean siphovirus: a new window into the cyanobacterial 'mobilome'. Environ Microbiol 11:2935-2951

Swingley WD, Blankenship RE, Raymond J (2008) Integrating Markov clustering and molecular phylogenetics to reconstruct the cyanobacterial species tree from conserved protein families. Mol Biol Evol 25:643-654

Timp W, Mirsaidov U, Matsudaira P, Timp G (2009) Jamming prokaryotic cell-to-cell communications in a model biofilm. Lab Chip 9:925-934

Van Wagoner RM, Drummond AK, Wright JLC (2007) Biogenetic diversity of cyanobacterial metabolites. In: Laskin AI, Sariaslani S, Gadd GM (eds) Advances in applied microbiology. Elsevier, Amsterdam, pp 89-217

Ward DM, Cohan FM, Bhaya D, Heidelberg JF, Kuhl M, Grossman A (2008) Genomics, environmental genomics and the issue of microbial species. Heredity 100:207-219

Wase NV, Wright PC (2008) Systems biology of cyanobacterial secondary metabolite production and its role in drug discovery. Expert Opin Drug Discov 3:903-929

Waters CM, Bassler BL (2005) Quorum sensing: cell-to-cell communication in bacteria. Annu Rev Cell Dev Biol 21:319-346

Whitchurch CB, Tolker-Nielsen T, Ragas PC, Mattick JS (2002) Extracellular DNA required for bacterial biofilm formation. Science 295:1487-1487

Whitehead NA, Barnard AM, Slater H, Simpson NJ, Salmond GP (2001) Quorum-sensing in Gram-negative bacteria. FEMS Microbiol Rev 25:365-404

Whitfield C, Naismith JH (2008) Periplasmic export machines for outer membrane assembly. Curr Opin Struct Biol 18:466-474

Whitton BA, Grainger SLJ, Hawley GRW, Simon JW (1991) Cellbound and extracellular phosphatase activities of cyanobacterial isolates. Microb Ecol 21:85-98 
Whitton BA, Al-Shehri AH, Ellwood NTW, Turner BL (2005) Ecological aspects of phosphatase activity in cyanobacteria, eukaryotic algae and bryophytes. In: Turner BL, Frossard E, Baldwin E (eds) Organic phosphorus in the environment. CABU Publishing, Wallingford/Cambridge, pp 205-241, 399 pp

Wieneke R, Klein S, Geyer A, Loos E (2007) Structural and functional characterization of galactooligosaccharides in Nostoc commune: beta-D-galactofuranosyl-(1->6)-[beta-D-galactofuranosyl-(1->6)] (2)-beta-D-1,4-anhydrogalactitol and beta-(1->6)-galactofuranosylated homologues. Carbohydr Res 342:2757-2765

Wood SA, Mountfort D, Selwood AI, Holland PT, Puddick J, Cary SC (2008) Widespread distribution and identification of eight novel microcystins in Antarctic cyanobacterial mats. Appl Environ Microbiol 74:7243-7251

Wright DJ, Smith SC, Joardar V, Scherer S, Jervis J, Warren A et al (2005) UV irradiation and desiccation modulate the three-dimensional extracellular matrix of Nostoc commune (cyanobacteria). J Biol Chem 280:40271-40281

Wu J, Xi C (2009) Evaluation of different methods for extracting extracellular DNA from the biofilm matrix. Appl Environ Microbiol 75:5390-5395

Yamaguchi M, Ogawa T, Muramoto K, Kamio Y, Jimbo M, Kamiya H (1999) Isolation and characterization of a mannan-binding lectin from the freshwater cyanobacterium (blue-green algae) Microcystis viridis. Biochem Biophys Res Commun 265:703-708
Yamasaki Y, Shikata T, Nukata A, Ichiki S, Nagasoe S, Matsubara T et al (2009) Extracellular polysaccharide-protein complexes of a harmful alga mediate the allelopathic control it exerts within the phytoplankton community. ISME J 3:808-817

Yang F, Bewley CA, Louis JM, Gustafson KR, Boyd MR, Gronenborn AM et al (1999) Crystal structure of cyanovirin-N, a potent HIV-inactivating protein, shows unexpected domain swapping. J Mol Biol 288:403-412

Yeager CM, Kornosky JL, Morgan RE, Cain EC, Garcia-Pichel F, Housman DC et al (2007) Three distinct clades of cultured heterocystous cyanobacteria constitute the dominant $\mathrm{N}_{2}$-fixing members of biological soil crusts of the Colorado Plateau, USA. FEMS Microbiol Ecol 60:85-97

Yoon HS, Golden JW (1998) Heterocyst pattern formation controlled by a diffusible peptide. Science 282:935-938

Yoshimura H, Okamoto S, Tsumuraya Y, Ohmori M (2007) Group 3 sigma factor gene, sigJ, a key regulator of desiccation tolerance, regulates the synthesis of extracellular polysaccharide in cyanobacterium Anabaena sp. strain PCC 7120. DNA Res 14:13-24

Zhaxybayeva O, Gogarten JP, Charlebois RL, Doolittle WF, Papke RT (2006) Phylogenetic analyses of cyanobacterial genomes: quantification of horizontal gene transfer events. Genome Res 16:1099-1108

Zilliges Y, Kehr J-C, Mikkat S, Bouchier C, Tandeau de Marsac N, Borner T et al (2008) An extracellular glycoprotein is implicated in cell-cell contacts in the toxic cyanobacterium Microcystis aeruginosa PCC 7806. J Bacteriol 190:2871-2879 